
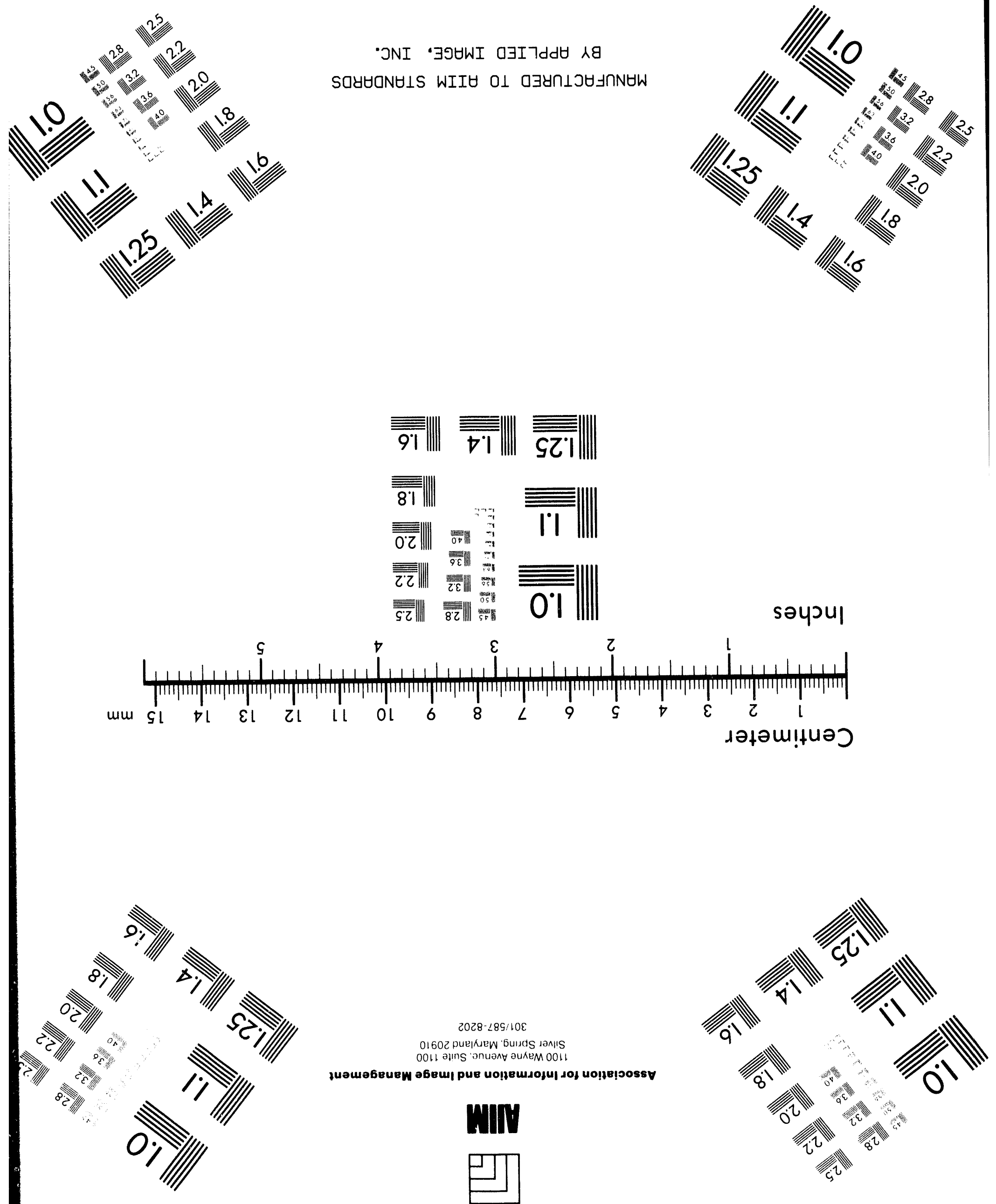

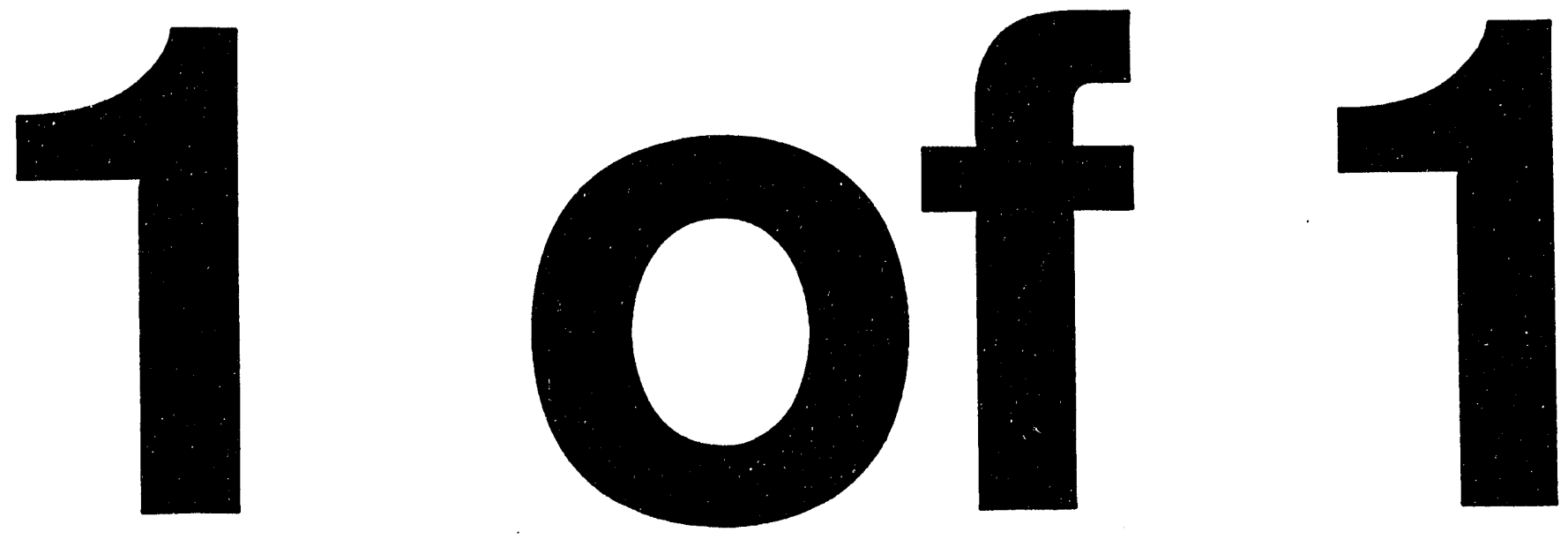


\title{
SYSTEM SAFETY ANALYSIS OF AN AUTONOMOUS MOBILE ROBOT
}

BY

\author{
RONALD J. BARTOS
}

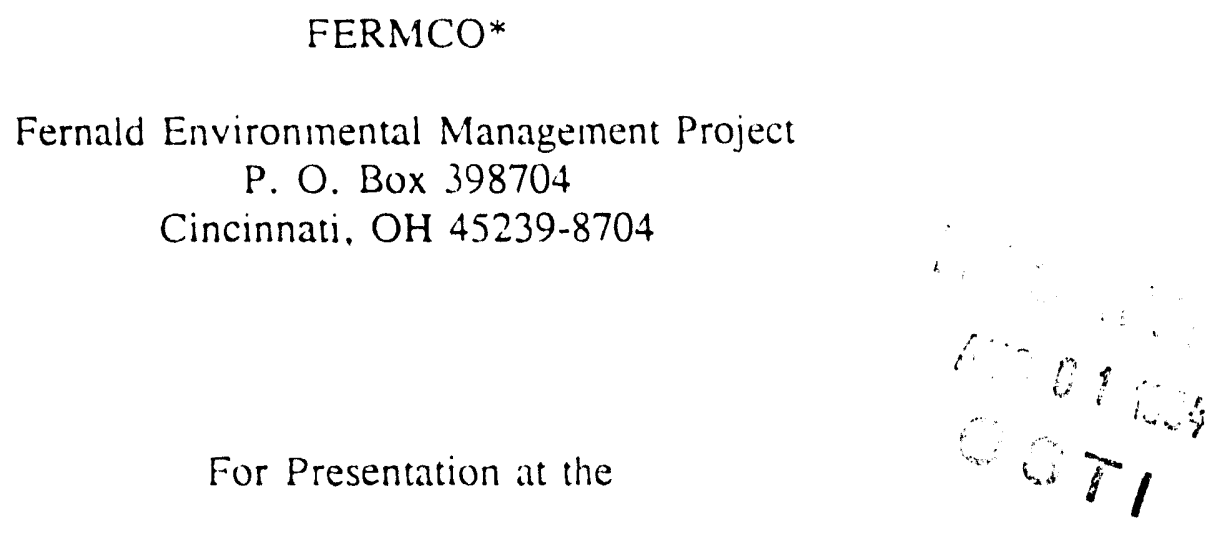

12th International System Safety Conterence

New Orleans. Louisiana

July $5-10,1994$

DISCLAIMER

\begin{abstract}
This report was prepared as an account of work sponsored by an agency of the United States Government. Neither the United States Government nor any agency thereof, nor any of their employees, makes any warranty, express or implied, or assumes any legal liability or responsibility for the accuracy, completeness, or usefulness of any information, apparatus, product, or process disclosed, or represents that its use would not infringe privately owned rights. Reference herein to any specific commercial product, process, or service by trade name, trademark. manufacturer, or otherwise does not necessarily constitute or imply its endorsement, recommendation, or favoring by the United States Government or any agency thereof. The views and opinions of authors expressed herein do not necessarily state or reflect those of the United States Government or any agency thereof.
\end{abstract}

* Fernald Environmental Restoration Management Corporation with the U. S. Department of Energy under Contract No. DE-AC05-92OR21972. 


\begin{abstract}
SYSTEM SAFETY ANALYSIS OF AN AUTONOMOUS MOBILE ROBOT
\end{abstract}

Ronald J. Bartos

\begin{abstract}
Analysis of the safety of operating and maintaining the Stored Waste Autonomous Mobile Inspector (SWAMI) II in a hazardous environment at the Fernald Environmental Management Project (FEMP) was completed. The SWAMI II is a version of a commercial robot, the HelpMate ${ }^{\text {Tu }}$ robot produced by the Transitions Research Corporation, which is being updated to incorporate the systems required for inspecting mixed toxic chemical and radioactive waste drums at the FEMP. It also has modified obstacle detection and collision avoidance subsystems. The robot will autonomously travel down the aisles in storage warehouses to racord images of containers and collect other data which are transmitted to an inspector at a remote computer terminal. A previous study showed the SWAMI II has economic feasibility. The SWAMI II will more accurately locate radioactive contamination than human inspectors. This thesis includes a System Safety Hazard Analysis and a quantitative Fault Tree Analysis (FTA). The objectives of the analyses are to prevent potentially serious events and to derive a comprehensive set of safety requirements from which the safety of the SWAMI II and other autonomous mobile robots can be evaluated. The Computer-Aided Fault Tree Analysis $\left(\right.$ CAFTA $\left.^{\circ}\right)$ sotitware is utilized for the FTA. The FTA shows that more than $99 \%$ of the safety risk occurs during maintenance, and that when the derived safety requirements are implemented the rate of serious events is reduced to below one event per million operating hours. Training and procedures in SWAMI II operation and maintenance provide an added safety margin. This study will promote the safe use of the SWAMI II and other autonomous mobile robots in the emerging technology of mobile robotic inspection.
\end{abstract}




\section{ACKNOWLEDGEMENTS}

The author gratefully acknowledges the assistance of the professionals at the Fernald Environmental Restoration and Management Corporation, especially Brack Hazen, the Savannah River Technology Center, and the Transitions Research Corporation in the preparation of this paper.

Thanks go to the University of Cincinnati for the use of their CAFTA $^{\oplus}$ software which was instrumental in preparing this analysis. I express my appreciation to Dr. Richard Shell and Dr. Ernest Hall, and particularly to Dr. Rodney Simmons who also served as my advisor during iny graduate study.

\section{DISCLAIMER}

This paper was prepared as an account of work sponsored by an agency of the United States Government. Reference herein to any specific commercial product, process, or service by trade name, trademark, manufacturer, or otherwise does not constitute or imply its endorsement, recommendation, or favoring by the United States Government or any agency thereof. The views and opinions of authors expressed herein do not necessarily state or reflect those of the United States Government, or any agency thereof or Fernald Environmental Management Corporation, its affiliates or its parent companies.

\section{COPYRIGHT}

By acceptance of this article, the publisher and/or recipient acknowledges the U. S. Government's right to retain a non-exclusive, royalty-free license in and to any copyright covering this paper. 
ABSTRACT $\ldots \ldots \ldots \ldots \ldots \ldots \ldots \ldots \ldots \ldots \ldots \ldots \ldots \ldots \ldots \ldots$

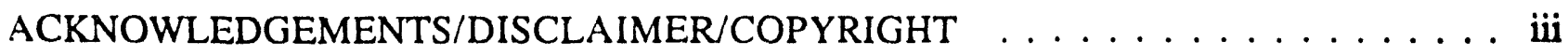

TABLE OF CONTENTS $\ldots \ldots \ldots \ldots \ldots \ldots \ldots \ldots$

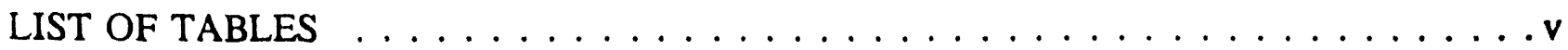

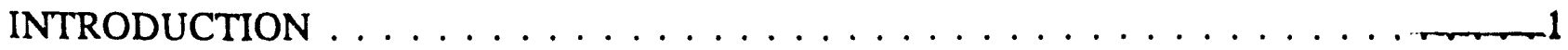

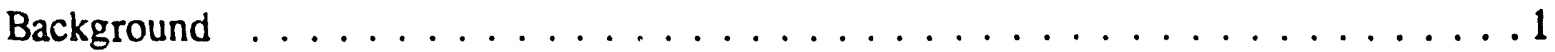

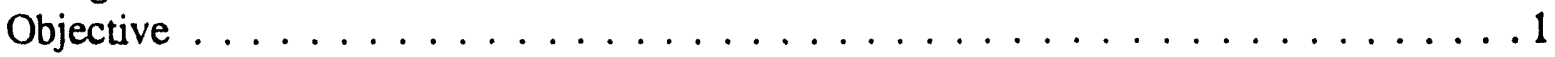

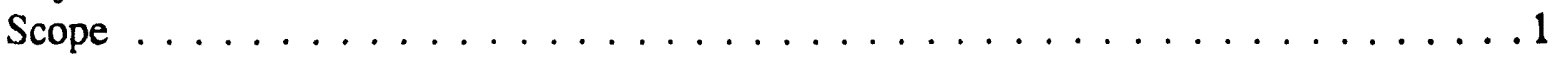

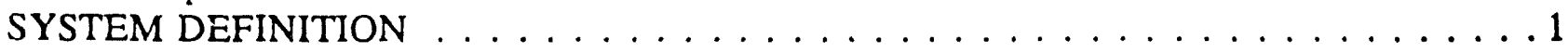

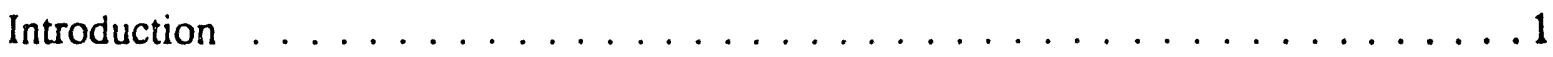

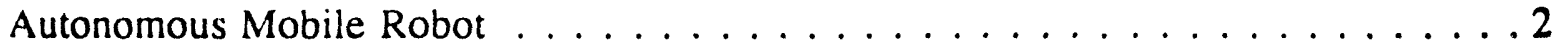

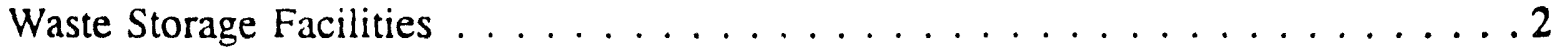

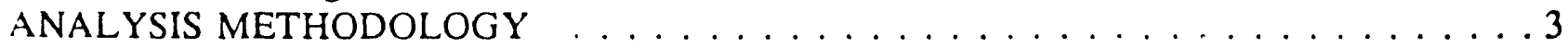

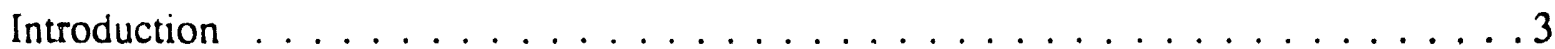

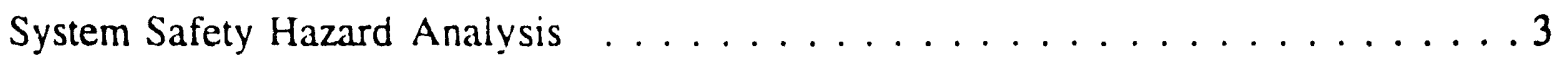

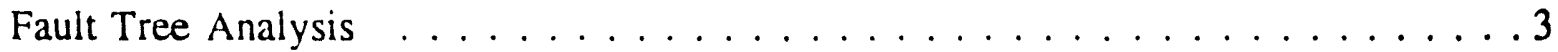

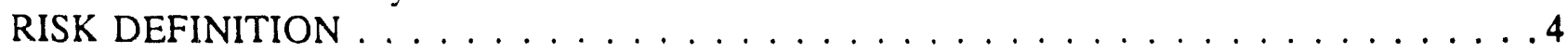

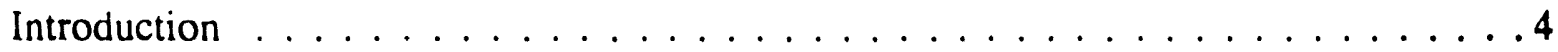

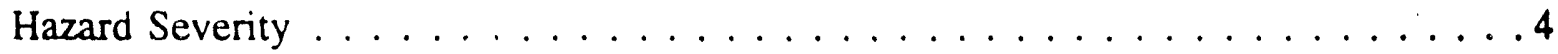

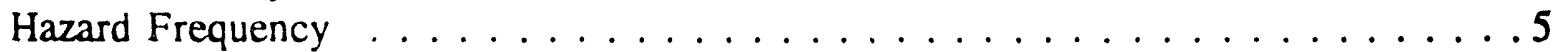

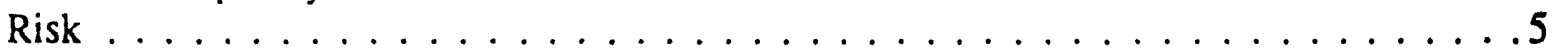

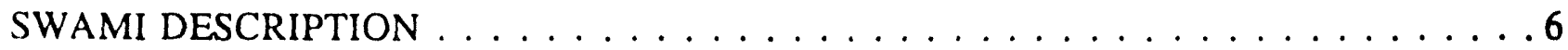

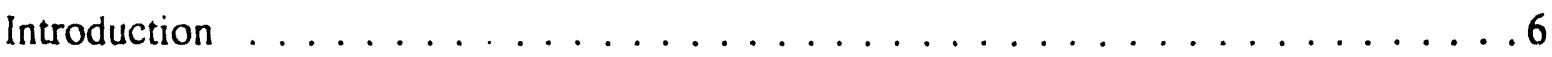

Physical Characteristics. Size and Movement .............. 6

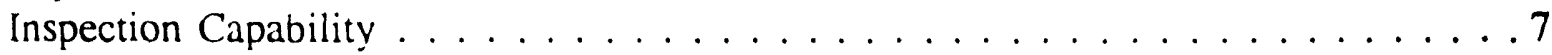

Location Determination and Obstacle Avoidance . . . . . . . . . . . . . . 7

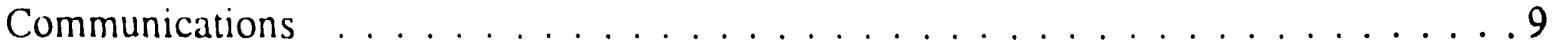

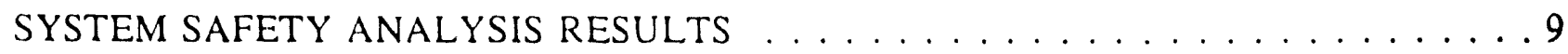

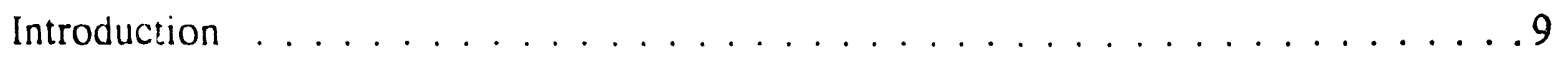

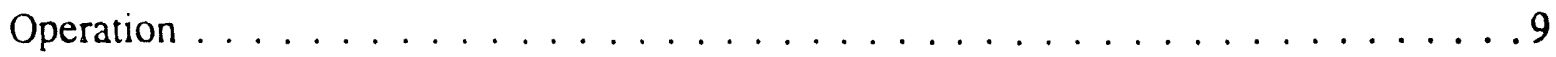

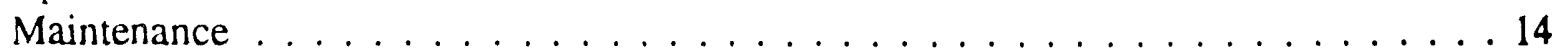

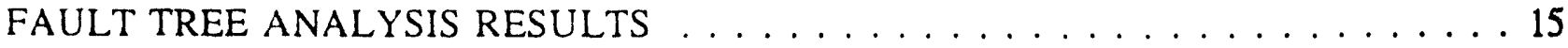

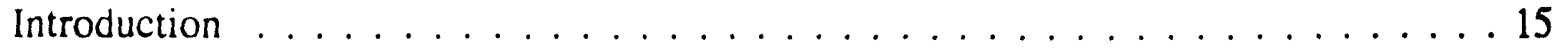

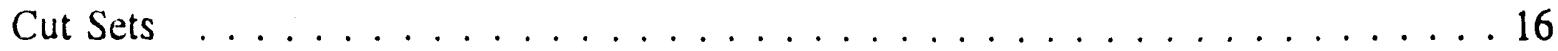

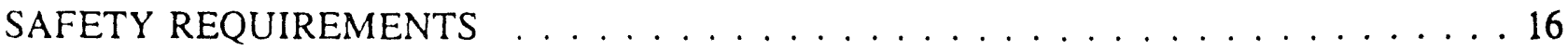

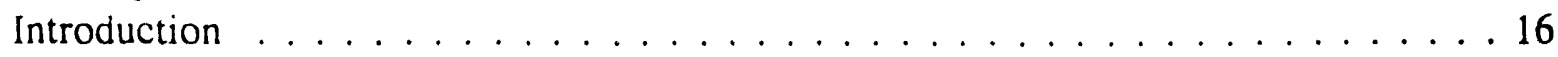

ANSI/RIA R15.06 Industrial Robots and Robot Systems . . . . . . . . . . . 18

ANSI B56.5 Automated Guided Vehicles . . . . . . . . . . . . . . . . . 19

International Labour Organization . . . . . . . . . . . . . . . . . . . . 20

Fault Tree Analysis . . . . . . . . . . . . . . . . . . 20

System Safety Hazard Analysis . . . . . . . . . . . . . . . . 21 
TABLE OF CONTENTS continued

Page

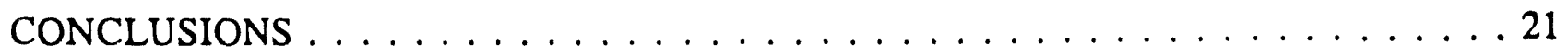

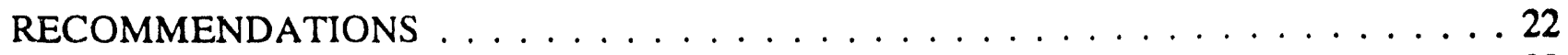

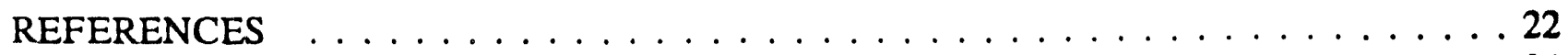

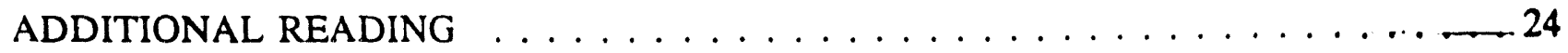

LIST OF TABLES

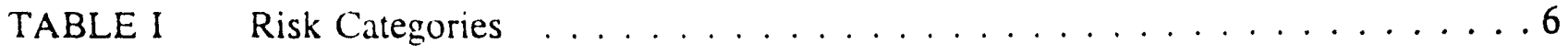

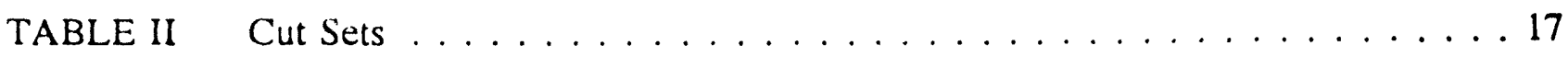


Background

\section{INTRODUCTION}

There are over 240,000 cubic meters of mixed toxic chemical and low level radioactive waste accumulated at several major Department of Energy (DOE) sites, including the Fernald Environmental Management Project (FEMP) in Fernald, Ohio. Anticipated decommissioning of these facilities is expected to generate 900,000 cubic meters of mixed low level waste, requiring additional storage. (1) Weekly inspections of these containers are required by both the United States Environmental Protection Agency (EPA) under the Resource Conservation and Recovery Act (RCRA) (2) and the Ohio EPA under the Ohio Administrative Code. ${ }^{(3)}$ The purpose of the inspections is to verify inventories and to prevent waste containers from leaking by identifying drums that have degraded. The containers at all DOE waste storage facilities are currently being inspected manually. There are plans to test an autonomous mobile robot at the FEMP to complete this function in order to remove workers from this potentially hazardous task. It is anticipated that this emerging mobile robotic inspection technology will be expanded to other hazardous materials inspection applications after the successful implementation of the Stored Waste Autonomous Mobile Inspector (SWAMI) at the FEMP.

\section{Objective}

The purpose of this study is two-fold:

1. To identify potential safety hazards of operating and maintaining the SWAMI II and give recommendations in order to reduce the rate of death/serious injury to below one event per million operating hours.

2. To derive a set of safety requirements applicable to the design, operation, and maintenance of the SWAMI II and other autonomous mobile robots from which their safety risk can be evaluated.

$\underline{\text { Scope }}$

This study addresses the robotic inspection of 55-gallon drums in two storage facilites at the FEMP. These facilites are Building 79-A, also known as the Plant 6 Warehouse, which currently stores 1,719 drums and Tension Support (TS) structure TS-5, which now holds 5,418 drums, but can hold up to 12,000 55-gallon drums. ${ }^{(4)}$ The research also addresses the safety of routine maintenance of the robot including battery recharging.

\section{SYSTEM DEFINITION}

\section{Introduction}

The system is defined in order to specifically limit the scope of the analysis. The SWAMI system is detined as the robot itself, the facilities in which it will be operated and 
maintained, nearby facilities, the immediate environment, and workers in the facilities. The SWAMI and the facilities will be explained further below.

\section{Autonomous Mobile Robot}

The SWAMI II is funded by the DOE through the Office of Environmental Restoration and Waste Management (ER/WM). The ER/WM is responsible for the clean-up and proper disposal of contaminated waste, buildings, process equipment and land at most DOE. sites. The SWAMI II robot is being developed and integrated at the Savannah River Technology Center (SRTC) where the robot's design is coordinated to assist in Mixed Waste Operations. The SRTC development includes the fabrication and test of a first prototype, SWAMI I, before the second field demonstration system, SWAMI II, is built for the FEMP. Both robots are commercially available units which will be updated with additional video, radiation sensing, and bar code scanning equipment for operations at the FEMP. The SWAMI II's design and specification will benefit from lessons learned from the SWAMI I testing. Pattern recognition software will later be added to SWAMI II to allow the robot to evaluate container images it collects on its own, rather than requiring an inspector to evaluate the images. Even so, SWAMI II will reduce the radiation dose currently received by inspectors and prevent potential radioactive and chemical contamination of inspectors. ${ }^{(5)}$ Performing the inspections with the SWAMI II has been shown to be economically feasible. ${ }^{(6)}$ This analysis will be addressing the SWAMI II as it is currently configured.

\section{Waste Storage Facilities}

The FEMP is a government-owned, contractor-operated facility that refined, smelted and machined high quality uranium metal for the DOE for over 30 years. Production stopped in 1989 and now the sole mission is environmental remediation and waste management. The 136acre former production area is situated on 1050 acres of land about 18 miles northwest of Cincinnati, Ohio. Since December 1992 it has been managed by the Fernald Environmental Restoration Management Corporation (FERMCO), a new corporation founded by several teaming partners led by Fluor Daniel.

In 1989 the site was placed on the National Priorities List (NPL) by the U. S. EPA because it is situated over a large aquifer supplying drinking water to several communities and because of the large amount of radioactive and chemical waste stored on the site. Compared to other DOE sites the radiation levels at the FEMP are low, although the total amount of radioactively contaminated material is high. In addition to being the first DOE site to undergo complete shutdown and environmental restoration, the FEMP will be a test site for technologies that will later be used for even larger cleanups at other DOE sites.

Because the FEMP is listed as a contaminated site on the NPL, the FEMP must follow the remediation steps outlined in the Comprehensive Environmental Response, Compensation and Liability Act (CERCLA) ${ }^{(\pi)}$ while also adhering to RCRA regulations that cover the generation, storage, and disposal of hazardous wastes. The drums to be in pected are mixed toxic chemical and radioactive wastes. The waste is classified as RCRA waste due to corrosivity and has been radioactively contaminated during the production process. ${ }^{(8)}$ 


\section{ANALYSIS METHODOLOGY}

Introduction

The American National Standards Institute (ANSI) standard on robotics safety, (9) ANSI/RIA R15.06, addresses several requirements for risk assessment of robotics systems. Although this standard explicitly excludes mobile robots from its scope, it is prudent to follow its requirements which are judged applicable to mobile robots. ANSI/RIA R15.06 borrowed requirements for risk assessment from the draft International Organization for Standardization (ISO), ISO/DP 10218. ${ }^{10}$ This risk assessment should consider:

- The size, speed, and capacity of the robot.

- The application and process.

- The anticipated tasks required for continuous operation.

- The hazards associated with each task.

- The anticipated failure modes.

- The probability of occurrence and severity of injuries.

The analysis of the SWAMI operation and maintenance system uses two system safety analysis techniques: System Safety Hazard Analysis (SSHA) and Fault Tree Analysis (FTA). These two types of analysis are described in the sections that follow.

\section{System Safety Hazard Analysis}

The purpose of a SSHA is to identify all the major hazards and sources of energy presented by a system. The analysis concentrates on energy sources which could produce the most severe undesired events in both normal and abnormal conditions. The hazards are ranked according to their risk, and the hazards with the highest risk are then selected for further study using other, more detailed analysis techniques. Risk is defined on page 4 . For this study, the hazard with the highest risk is a person being killed or seriously injured by the SWAMI. The circumstances and failures which could lead to this event are further analyzed in the Fault Tree Analysis.

The SSHA is organized in a tabular format with column headings of Hazard, Cause, Effects, and Corrective Action. As each potential hazard is identified. so are the hazard's causes, its worst credible effects on the system, and what corrective actions could be taken to eliminate or control the hazard in order to prevent the effects from occurring. The SSHA results are discussed starting on page 9 .

\section{Fault Tree Analysis}

Fault Tree Analysis (FTA) uses deductive reasoning and a top-down approach to logically describe how a selected Top Event could occur. The Top Event selected in this study is "Serious injury or death during SWAMII Operation or Maintenance". All the ways that a human could be seriously injured or killed by the SWAMI are hypothesized. including mechanical and 
software failures, unforeseen circumstances, normal and abnormal operating and maintenance conditions, and human error. The FTA is different from other types of system safety analyses, such as Failure Modes and Effects Analysis (FMEA), since it analyzes the effects of what are perceived to be normal design and operating conditions in addition to failures, and also because it studies combinations of failures, not just single failures. These events, or combinations of events, which lead to the Top Event are termed Cut Sets.

An FTA can be performed qualitatively or quantitatively. A qualitative FTA does not assign frequency rates to events, whereas a quantitative FTA does. This analysis-used-a quantitative FTA. Frequency rates are assigned to each failure event and circumstance in the FTA. The rate of the Top Event occurring is calculated by summing the rates of all the Cut Sets. The failure and event rates for this analysis are estimated using the best available data for hardware and software failures, human error, and estimates of other conditions. Estimates of failure and event rates are assigned according to the hazard frequency definitions described in Hazard Frequency on page 5.

The FTA is performed by the Personal Computer-based software program called CAFTA $^{\circ}$ (Computer Aided Fault Tree Analysis), Version 2.1, developed by Science Applications International Corporation. The fault tree logic and event rates are entered into the program and CAFTA ${ }^{\circ}$ calculates the frequency rates of the Cut Sets which will result in the Top Event and of the Top Event itself. The SWAMI II FTA is summarized beginning on page 15. For more information on the FTA methodology the reader is referred to the Fault Tree Handbook, NUREG-0492. (1)

\section{RISK DEFINITION}

\section{Introduction}

Safety risk is defined as a combination of hazard severity and hazard frequency. Hazard severity is determined by the worst case. credible potential accident which could result from an identified hazard. Hazard frequency is determined through actual historical data of similar systems, industry experience, or engineering judgement. The hazard severity and hazard frequency categories are defined with descriptive terms. These categories are described below.

\section{Hazard Severity}

The following terms are used to describe hazard severity based on the worst credible effect the hazard may have on the system.

I. Catastrophic - May cause death, system loss, or irreparable environmental damage.

II. Critical - May cause serious injury or occupational illness, major system damage, or serious environmental damage.

III. Marginal - May cause minor injury or occupational illness, minor system damage, or minor environmental damage. 
IV. Negligible - Causes less than minor injury or occupational illness, minor system damage, or minor environmental damage.

\section{Hazard Frequency}

The frequencies of failures and basic events are assigned from known failure rates of hardware and software, and estimates of other events, such as human error and other circumstances. Failure rates of some components were obtained from Transitions Research Corporation's (TRC) historical records of failures. Other failure rates for mechanical components and human error rates were taken from WASH-1400(12) and MIL-HDBK-217F, Reliability Prediction of Electronic Equipment. ${ }^{(13)}$ Failure rates for mechanical components taken from WASH-1400 used the upper bound failure rate listed for industrial experience. When failure rates were unknown, they were estimated using engineering judgement according to the frequency categories found in proposed DOE-STD-3005, Evaluation Guidelines for Accident Analysis and Safery Structures, Systems, and Components. (14) The following frequency categories are used in this analysis. Hours are detined as SWAMI II fleet operating hours of the system in all locations.

A. Anticipated - Events for which estimation techniques indicate a frequency of occurrence greater than or equal to 0.01 events per hour. These events are expected to occur in the system since they may be thought of as "one event occurring at least every 100 hours of operation."

B. Unlikely - Events for which estimation techniques indicate a frequency of occurrence less than $1 E-02$ events per hour and greater than or equal to $1 E-04$ events per hour. These events are unlikely to occur in the lifetime of the system since one event would be expected to occur every $100-10,000$ hours of operation.

C. Extremely unlikely - Events for which estimation techniques indicate a frequency of occurrence less than 1 E-04 events/hour and greater than or equal to IE-06 cvents/ hour. These events are considered to be extremely unlikely and are borderline incredible events since one event would be expected every 10,000 - 1,000,000 operating hours.

D. Incredible - Events for which estimation techniques indicate a frequency of occurrence less than 1E-06 events/hour. These events are not considered credible, and their consequences are not routinely required to be calculated.

$\underline{\text { Risk }}$

One of the purposes of this analysis is to prevent death and serious injury during SWAMI operation and maintenance. The Top Event in the Fault Tree Analysis is "Serious injury or death during SWAMI Operation or Maintenance". Per the hazard severity definitions on page 4. death is a Catastrophic hazard and serious injury is a Critical hazard. Therefore, hazards with effects in the severity categories of Catastrophic and Critical are considered unacceptable for this analysis. But. some of these hazards are not a concern since their estimated rates of 
occurrence are extremely low. Therefore, only Catastrophic or Critical hazards with frequencies of Anticipated, Unlikely, or Extremely Untikely were judged to be of an unacceptable nature for this analysis. These six categories of risk are marked with an "X" in TABLE I below.

TABLE I Risk Categories

\begin{tabular}{|c|c|c|c|c|}
\hline $\begin{array}{l}\text { Frequency } \rightarrow \\
\text { Severity } \downarrow\end{array}$ & $\begin{array}{l}\text { Anticipated } \\
\lambda \geq 1 \mathrm{E}-02\end{array}$ & $\begin{array}{c}\text { Unlikely } \\
1 \mathrm{E}-02>\lambda \geq 1 \mathrm{E}-04\end{array}$ & $\begin{array}{c}\text { Extremely } \\
\text { Unlikely } \\
1 \mathrm{E}-04>\lambda \geq 1 \mathrm{E}-06\end{array}$ & $\begin{array}{l}\text { Incredible } \\
\lambda<1 \mathrm{E}-06\end{array}$ \\
\hline Catastrophic & $\mathrm{x}$ & $\mathrm{x}$ & $\mathrm{x}$ & \\
\hline Critical & $\mathrm{x}$ & $\mathrm{x}$ & $x$ & \\
\hline \multicolumn{5}{|l|}{ Marginal } \\
\hline Negligible & & & & \\
\hline
\end{tabular}

The six marked risk categories define unacceptable safety risks. $\lambda=$ frequency rate, events per operating hour

\section{SWAMI DESCRIPTION}

Introduction

The base of the SWAMI is a HelpMate ${ }^{\text {Tx }}$ autonomous mobile robot designed and produced by TRC. Subsystems have been added and modified on the HelpMate ${ }^{\text {TM }}$ in order for the SWAMI to meet its functional requirements at the FEMP. It is planned that the SWAMI will also have additional capabilities, such as backward movement and sensors facing the rear, that the HelpMate ${ }^{\text {ru }}$ does not.

\section{Physical Characteristics, Size, and Movement}

The SWAMI's size permits it to tit down the aisles at the two FEMP warehouses considered in this study. It is planned that the SWAMI will be used during the night shift so it won't be disturbed by people or equipment in the warehouses during the day. The robot is driven by a tixed axle with two parallel wheels centrally located on its base. Four idle casters are situated on its corners for stability.

The robot can be turned by counter-rotating the two drive wheels. An advantage of this differential drive steering is that the turning radius of the SWAMI is zero, ${ }^{(15)}$ therefore the SWAMI can adequately turn the corners of the storage warehouses. A performance disadvantage of these turning mechanics is that the SWAMI cannot instantaneously change direction since it can't move parallel to its fixed axle. This actually is a safety advantage because it will allow nearby personnel more insight into its movement. 
Paths for the robot are specified through AutoCAD-generated files that specify points through which the robot stops or passes. The path points form line segments that the robot follows. Two other types of lines can be put in the AutoCAD file to define the robot's movement. One line defines areas that the robot should never enter, such as walls of a building. The other line discourages travel across it except in collision avoidance situations. The SWAMI will travel at $1 \mathrm{in} / \mathrm{sec}$, which will allow it to survey about 2400 feet of aisleway in an 8-hour shift.

The robot can operate for 8 hours without its battery needing recharging. The-two storage warehouses will have battery recharging equipment. It has adequate torque in its drive wheels to go up the inclined ramps over the curbs in the warehouses. The SWAMI will operate in the climate of the warehouses, from $-10^{\circ}$ to $105^{\circ} \mathrm{F}$. and in humidity from $0-100 \%$.

The main navigation package used by TRC relies on dead reckoning. With this method, the robot's heading and distance traveled is measured by the rotations of its drive wheels. Wheel slip and uneven floors can cause this estimation to become inaccurate over long distances. SWAMI uses a NavTech range finder to update its position. More details on this subsystem are on page 8.

Building 79-A has a dry type fire sprinkler system which does not have water throughout the piping system. This type of system reduces the potential for water to leak onto the floor or onto the SWAMI. TS-5 does not have a fire sprinkler system.

Inspection Capability

The SWAMI will be thorough in its inspection of the containers and in its radiation survey of the aisles. It will identify drums from their bar code labels, record their locations, and then colleci their images using Charge Coupled Device cameras and strobe lighting. Strobes are used to save on power by only flashing the lights intermittently. The bar code labels must be within $40^{\circ}$ of the tacing aisle and anywhere on the middle third of the drum. The SWAMI will generate a report of drum locations to verify the presence and location of the waste inventory to meet RCRA requirements. The robot will have sensors on board to allow it to identify deformities in the drums. SWAMI will present the images it has captured to an inspector at a remote base computer station.

The vision system can detect rust spots of $1 / 4$-inch diameter or larger. It will also detect vertical streaks larger than $1 / 4$-inch wide and six inches long. The structured lighting system can find dents greater than one inch deep, 1.5 inches wide, and two inches long. The sensors, lights, and cameras will be mounted on vertical masts in order to position them at the correct centerline height of the drums.

The SWAMI has a gas proportional ionization detection system for radiation surveys of alpha and beta/gamma radiation in the aisles. The system can identify contamination within its path of greater than 500 counts per minute.

\section{Location Determination and Obstacle Avoidance}

A principal concern of the SWAMI is its ability to identify its location, detect obstacles and avoid collisions with people, drums. and other objects. Four separate sensor systems further 
explained below are responsible for detecting impending collisions: ultrasonic range finders, laser scanners, tactile sensors, and a bumper. Ultrasonics are also used for position verification, as is a NavTech range finder optical system.

Experience with the HelpMate ${ }^{\mathrm{m}}$ robot shows that its obstacle avoidance systems have been successfully demonstrated in the busy corridors of hospitals. The SWAMI has functionally redundant systems to detect obstacles, and navigation software to allow it to modify its path in order to avoid fixed and moving obstacles in its preplanned path and then return to its original path. The maximum deviation from its original path can be programmed into the path planning software. ${ }^{(16)}$

Ultrasonic Range Finder - The ultrasonic range finder is used for both position verification and obstacle detection. For position verification, the SWAMI uses ultrasonic sensors to locate fixed features in the area it's traveling. These sensors update the robot's internal position to keep it accurate. Doorways and ends of halls can be used for this purpose. The sensors fire individually to decrease crosstalk, that is, the transmitted pulse from one sensor cannot be received by another sensor to cause an erroneous measurement. ${ }^{15.17}$ The SWAMI tracks its position with an accuracy of one inch.

The SWAMI has two sensor packages positioned close to the floor on its left and right edges for collision avoidance. Each sensor package has four ultrasonic detectors that sweep $90^{\circ}$ from straight ahead to straight sideways. These sensors are used to center the SWAMI in the middle of the aisle. The sensor packages include photodetectors that return a signal upon locating a strip of reflective tape. These pieces of tape are placed around the facility and used to update the SWAMI's internal position estimate as a second means of position verification.

Several ultrasonic sensors on the robot detect the presence and range of objects in its path or beside it. These sensors have a range of 17 inches to 30 feet and emit at several frequencies since some soft materials absorb sound at some of the emitted frequencies. The pulse rate can be high enough to approximate continuous sensing.

Ultrasonic sensing has one advantage over optical sensing in that it can be made reasonably fail-sate. Since there is a measurable delay in time between the transmitted pulse and the first allowable return pulse. the transmitted pulse can be "heard" to determine proper transmitter operation. This is impractical to accomplish with optics.

Laser Scanners - The laser scanner is one of the backup systems used for obstacle avoidance that ultrasonics may miss. The system consists of a low power laser and a camera system. This Class 2 laser operates at $670 \mathrm{~nm}(0.67 \mu \mathrm{m})$ in the visible range at $1.0 \mathrm{~mW}$ maximum power. Laser (optic) sensing uses the reflective characterisitics of objects for detection. If an obstacle appears, the taser light will renlect back to the camera and appear as light on the image plane.

NavTech Range Finder - A third position verification system available on the robot is a NavTech range finder located in the half dome-shaped object on top of the SWAMI. It is an optical system that scans the area around the robot for passive beacons placed in fixed, known locations. The beacons are made of one-inch wide strips of reflective tape spaced around the facility so that multiple beacons can be differentiated.(5) 
Tactile Sensors - Tactile sensors are mounted on the robot such that overhangs and other objects which may have been missed by ${ }^{\star}$ the previous two obstacle detection systems can be discovered. If tripped by these sensors, the robot stops immediately and goes into an obstacle avoidance routine whereby it uses the location of the tripped tactile sensor strip to determine the correct direction to travel to avoid the obstacle.

Front Bumper/Break Beam - In the event of the failure of the previous three obstacle detection systems, the robot has a front bumper with a photoelectric pair which notifies the unit if the light beam between the emitter and detector is broken. It will then back up and try to find a better path.

Emergency Stop Buttons - Two large mushroom-type emergency stop buttons on the top of the unit can be accessed by personnel in the unlikely case of failures of the other detection systems.

Communications

The SWAMI will be able to communicate with the base computer through radio frequency (RF) or through a wireless Ethernet system to transmit its location and path. ${ }^{(18)}$

\section{SYSTEM SAFETY HAZARD ANALYSIS RESULTS}

Introduction

The System Safety Hazard Analysis (SSHA) is divided into hazards occurring during operation and hazards occurring during maintenance. The results of the SSHA are presented in the discussion below.

\section{Operation}

\section{Ultrasonic Collision Avoidance System Hazards}

Error in ultrasonic range determination - Although the use of ultrasonics in obstacle detection and avoidance has been proven in some applications, ${ }^{(19)}$ this method does have some weaknesses. Ultrasonic sensing is a technique implemented by emitting a burst of ultrasonic energy forward from the vehicle and measuring the time from emission to reception of the reflected signal. Since sound travels at about 1000 feet per second and the distances sensed are typically under 20 feet, the pulse rate can be high enough to approximate continuous sensing.

The large angle over which sound energy propagates from the transducer face can result in multiple reflection paths. This source of error can be overcome with multiple sensors. ${ }^{(17)}$

Beam divergence can also be a problem to the extent that the ultrasound may not be able to see a seven foot high door because the beam has diverged to that size. Random electrical and ultrasonic noise can also lead to errors. ${ }^{(2)}$ 
The size and shape of the target, the acoustic absorption of the target, and the distance from the vehicle all affect signal strength: Thin objects can be missed by ultrasonics because of their small cross sections. A flat object at an acute angle to the path may never be seen. A thermal shear, such as that caused by an air curtain or an air conditioning vent, can appear as solid as a facility wall when viewed by ultrasonics. ${ }^{(21)}$ There can be a severe problem with specular reflection. (22) Piezoelectric transducers used in the ultrasonic system are sensitive to the orientation and nature of the target, and there are some problems measuring distances less than 8 inches. ${ }^{(23)}$

The large propagation angle tends to blur edges and corners. Many objects have surfaces that are smooth compared to the long acoustic wavelength (about 0.24 in) causing the transmitted sound to be specularly reflected, and so the nearest object may not cause the first echo. (24)

These shortcomings of the ultrasonic system can cause the SWAMI to miss obstacles in its path at a significant event rate. For this reason, ultrasonics should not be thought of as one subsystem in a redundant collision avoidance system, but more as a complementary system along with the laser system.

Object mater al absorbs transmitted ultrasound signal - The acoustic absorption of the target can affect the ability of the ultrasonic system to sense objects. Softer materials are able to absorb the transmitted pulse and a reflected signal will not be measured. ${ }^{(21)}$

Ultrasonic range determination is longer than actual due to cold ambient temperature Because ultrasound uses the speed of sound in air to determine the distance to objects, it is susceptible to temperature dependence. As the temperature of air decreases, its density increases and the speed of sound decreases. The speed of sound in air is inversely proportional to the density of air as shown in equation (1):

$$
v=(\beta / \rho)^{1 / 2}
$$

where $\begin{aligned} v & =\text { velocity of sound in air } \\ \beta & =\text { Bulk Modulus (elasticity) of air } \\ \rho & =\text { air density }\end{aligned}$

The range algorithm in the ultrasound subsystem software is typically calibrated for use at a normal indoor air temperature of about $71^{\circ} \mathrm{F}$. The safety concern is that the object is sensed farther away than it actually is, resulting in a collision with the object. This would occur when the actual temperature is colder than the calibrated (room) temperature. The SWAMI may be operating in temperatures as cold as $-10^{\circ} \mathrm{F}$ according to the System Specification ${ }^{(5)}$ since one of the storage warehouses is exposed to outside temperatures.

The speed of sound in air, $v$, is approximately:(2.5)

$$
\begin{aligned}
& v @ 71^{\circ} \mathrm{F}=1130 \mathrm{feet} / \mathrm{second} \\
& \mathrm{v} @-10^{\circ} \mathrm{F}=1040 \mathrm{feet} / \mathrm{second}
\end{aligned}
$$


If an object were actually 20 feet away, the reflection time at $-10^{\circ} \mathrm{F}$ would be calculated from equation (2):

$$
\mathrm{t}=20 \mathrm{ft} \div 1040 \mathrm{ft} / \mathrm{sec}=0.01923 \mathrm{sec}
$$

where $\mathrm{t}=$ reflection time $(\mathrm{sec})$

But, since the range algorithm is calibrated for room temperature, say $71^{\circ} \mathrm{F}$, SWAMI would calculate the distance from equation (3):

$$
\mathrm{d}=1130 \mathrm{ft} / \mathrm{sec} \times 0.01923 \mathrm{sec}=21.7 \mathrm{ft}
$$

where $\mathrm{d}=$ distance (feet)

This shows there could be a distance calculation error of up to 1.7 feet due to the ultrasonic system's use of a constant speed of sound instead of the actual speed at different temperatures. To make the ultrasonic range calculation more accurate, it is recommended that an ambient temperature sensor be included on the SWAMI, and a correction factor be added to the range algorithm to correct for the speed of sound due to changes in the temperature.

Ultrasonics sense object that isn't there - A thermal shear, such as is caused by an air curtain or an air conditioning vent, can appear as solid as a facility wall when viewed by ultrasonics. $^{(21)}$ After further consideration, it is not actually a safety hazard to sense objects that are not there, but it would have an effect on object detection performance and efficiency.

Noise blurs ultrasonic signals - Ambient noise in the upper acoustic spectrum can blur the reflected signal. ${ }^{(21)}$ Noise induced by vehicle vibration, possibly caused by the SWAMI moving over rough floor surfaces, can also generate false signals. This effect would make it more difficult for the SWAMI to perform its obstacle avoidance mission.

Ultrasonic system components fail causing loss of obstacle detection - Failure of the Central Processing Unit (CPU), also called the host computer, the ultrasonic emitter and receiver, subsystem wiring or connections, and obscured lenses could all contribute to failure of the SWAMI to sense an obstacle with the ultrasonic system.

Ultrasonic sysiems have one advantage over optical systems. Since there is a measurable time delay between the transmitted pulse and the first allowable return pulse, the transmitted pulse can be "heard" in order to determine correct transmitter operation. This feature should be included in the SWAMI's self-dingnostic capability.

Failures of electrical circuits, including the computer, account for the largest number of robot malfunctions. ${ }^{(26)}$ Analysis of the CPU identified the following failure modes: These are:

- Inherent failures of relays and boards.

- Electromagnetic interference from other nearby electrical components could cause signal errors. 
- Static electricity, especially in dry environments, can cause false signals.

- Wiring failures.

- Cable connection failures in electrically controlled robots provide for a significant class of failures. ${ }^{27}$ Signal integrity should be checked with the self-diagnostic system.

- Condensation leading to short circuits can be caused by rapidly moving the SWAMI from a hot to a cold environment. Procedures should prohibit such movement.

- The robot could become contaminated radiologically, chemically, or with water, leading to failure of some of the electrical systems. Water could contact the SWAMI from a leaking roof, leaking drums, or activation of the fire sprinkler system.

- $\quad$ CPU failure could be caused by software lockup.

- Since the SWAMI may be operating in ambient temperatures as high as $105^{\circ} \mathrm{F}$, overheating of the CPU may be a concern.

- Corrosion of components could be caused by dissimilar metals.

\section{Laser Collision Avoidance System Hazards}

With the laser system, an optical beam of light from a strobe bulb is emitted forward of the vehicle. Objects in the path of the vehicle reflect a portion of the light to create the detection signal. The laser system does not have as many conceptual weaknesses as the ultrasonic system, but some of its components have higher failure rates.

Highly reflective surface blinds laser system - The laser system uses the reflective characteristics of objects for detection and is therefore sensitive to highly reflective surfaces, ambient illumination, and smoke. Some optical units can be momentarily blinded by sudden exposure to strong sunlight. Most will be activated by highly retlective surfaces further than the normal activation range. Some colors and textures of clothing will not be reliably detected by optical systems. ${ }^{(21)}$ Also, this system works well on straight aisles, but loses reliability on curves. Highly reflective surfaces should be painted with nonretlective paint.

Personnel exposure to laser energy - Personnel exposed to laser energy could be injured. The power and wavelength of the laser used in AMRs should be determined and verified as safe for personr.el. The SWAMI uses a Class 2 continuou: wave laser which operates at $670 \mathrm{~nm}$ in the visible spectrum and at $1.0 \mathrm{~mW}$ maximum power, which is safe for personnel. A Class 2 laser is in a low risk category, but as a precaution a label must be put on the SWAMI and signs posted in the facilities to caution personnel not to stare at the beam. (28)

Components tail causing lack of obstacle detection - In addition to the strobe light source, the laser system includes emitter and receiver voards. emitter and receiver diodes, and a lens on both the emitter and receiver as a focusing device. The component with the highest failure rate is the strobe bulb, which has two reported failures in about 170.000 hours of HelpMate ${ }^{\text {th }}$ operation. ${ }^{(29)}$ 
Host computer fails causing loss of laser obstacle detection - These failures are common to the host computer failures for the ultrasonic system listed on pages $11-12$.

\section{Tactile system hazards}

The tactile sensor system uses individually wired strips of tape switch which are enabled upon contact.

Contact strip fails open causing loss of obstacle detection - Contact strips are easy to damage. They are normally open and close when they're actuated. Although it is possible to monitor the control circuit associated with the strips, it is not possible to monitor the contact strip itself and this is the item which is most susceptible to damage. Therefore, the selfdiagnostic circuit cannot detect if the strip is in good condition or if it has become contaminated. The tape switch does have a low threshold to detect contact -- less than one pound.

CPU fails causing loss of tactile system obstacle detection - The CPU failures listed on pages $11-12$ also apply to the tactile system.

\section{Bumper System Hazards}

Excessively high threshold for activation - The bumper relies on an activation force of 10 - 15 pounds. ${ }^{(29)}$ The bumper should be activated in no more than $8 \mathrm{lb}$ of force applied parallel to the floor. ${ }^{21.30)}$ An excessively high force needed to stop the robot may result in serious personnel injury.

Inadequate bumper travel - At its maximum speed, if the time it takes to stop the SWAMI is too long measured from the instant a person contacts the bumper until the robot stops, the bumper may exceed its spring travel and seriously injure the person. Bumper travel should be sufficient is d!low the SWAMI time to react without exceeding the bumper spring travel.

Photoelectric pair fails - Photoelectrics are susceptible to erratic behavior and unwelcome sensitivity to uncontrolled variables such as reflectance, ambient illumination, and smoke. ${ }^{(23)}$

\section{Emergency stop hazards}

Reliance on relays, CPU, or logic for emergency stop - If the emergency stop system design requires any intermediate logic or electrical controls, an emergency stop may not be completed since these intermediate components may have already failed.

Emergency stop components fail - The robot will not stop upon command if the buttons, wiring or connectors tail.

Human unable to reach emergency stop buttons - Location of the buttons only on the front of the SWAMI during backwards movement or panic caused by the emergency may not 
allow a person to activate the buttons successfully.

\section{Other Operational Hazards}

Drive system stop actuation fails - If the electromechanical braking system used to stop the SWAMI drive system fails, a person may be seriously injured.

High center of gravity - If the center of gravity (c.g.) of the SWAMI is too high up from the floor, the robnt may tip over from acceleration, deceleration, or travel up and down ramps. Ramps over the warehouse curbs are typically 1 on $12\left(4.76^{\circ}\right)$. The c.g. should be determined and the potential for tipping over should be verified.

Slippery floors - If the SWAM were to slide on a slippery floor or ramp during operation, it may result in a person being seriously injured. Floors or ramps may become slippery from leaking containers, leaking roofs, or activation of the fire sprinkler system.

SWAMI knocks over objects - If the SWAMI were to contact an object, like a stack of drums, and knock them over then a nearby person could be seriously injured. The torque developed by the SWAMI drive system should be determined and it should be verified that the robot cannot knock heavy objects over.

SWAMI RF energy inadvertently operates other equipment - Radiofrequency (RF) energy used in the SWAMI communication system could inadvertently activate other equipment, such as overhead doors or bridge cranes, and cause serious personnel injury. The potential for inadvertent activation should be determined and verified as safe.

SWAMI becomes contaminated - If the SWAMI were to come in contact with some of the waste stored in the warehouses during the inspection, either due to leaking containers or from the SWAMI knocking over a container, the resulting chemical and/or radiological contamination of the robot would require some type of decontamination. Decontamination typically involves washing the contaminated equipment with some type of solution. Washing the SWAMI with a liquid solution could result in damage to some of its equipment, especially electrical modules or software. Provisions should be made to decontaminate the SWAMI with methods which would not damage sensitive components on the robot.

\section{Maintenance}

It has been reported that a large proportion of accidents involving robots occur during non-standard operations, such as during repairs and maintenance. ${ }^{(31)}$ Although maintenance work will only account for a small percentage of the SWAMI's hazard exposure time, personnel safety during these times should not be discounted. In fact, workers will be in the closest proximity to the SWAMI during maintenance, so there will be much more exposure to SWAMI hazards during these times than during operational times. 
Personnel contact with high voltage - If a worker were to be exposed to high voltage (over 50 volts) during maintenance operations they may receive an electrical shock which could lead to serious injury or death. The proposed design calls for complete bonding and grounding of the electrical systems on the SWAMI. There are circuits carrying 500 volts across the strobe bulbs, the strobes have a 10,000 volt trigger, and the radiation detection system uses high voltage so there is potential for electrocution. The strobes have large capacitors which store voltage after power is removed from the robot. These electrical hazards assume that the worker can access these circuits and that there are no guards, barriers, or interlocks to prevent contact with them.

The design must adhere to the National Electrical Code $(N E C)^{(32)}$ standards for grounding and bonding (NEC Article 250), overcurrent protection (NEC Article 240), guarding, barriers, interlocks, and labeling. Capacitors should bleed down to below 50 volts within five minutes after power is removed from the SWAMI (NEC Article 460). Maintenance procedures must demand that circuits and capacitors be grounded before maintenance is begun. A lockout/tagout program should be in place to protect workers from inadvertently turning on power to the robot during maintenance.

Short circuit during maintenance causes fire - A short circuit during main tenance could lead to a fire on or near the SWAMI to which maintenance workers could be exposed. This hazard can be controlled by following the $N E C_{1}{ }^{(3 i)}$ and by proper storage of combustibles and flammable liquids in the maintenance area.

Recharging operation results in fire - Battery recharging can result in hydrogen gas production. Fire will result if there is an explosive atmosphere of hydrogen $(4 \%-75 \%)$ and an ignition source is present. This hazard can be controlled by providing sufficient area ventilation to preclude an explosive hydrogen atmosphere and by prohibiting ignition sources within 50 feet of the recharging operation.

Manual lifting of battery - The battery in the SWAMI's base weighs about 250 pounds. The battery will need to be removed for recharging and for some maintenance operations. Mechanical lifting devices should be provided for objects weighing over 56 pounds which need to be lifted over 1.5 feet. $^{(33)}$

\section{FAULT TREE ANALYSIS RESULTS}

\section{Introduction}

The top event of "Serious injury/death during SWAMI Operation or Maintenance" was selected as the event to analyze further using Fault Tree Analysis (FTA) since this event was the result of several of the hazards identified in the SSHA. The frequency of the top event was calculated to be 5.53 events per 1000 operating hours by the FTA. The analysis was completed without taking credit for safeguards which may currently be in the system for preventing the identified hazards since complete design information was not available. As an example, it was reported that the battery was on wheels to allow it to be removed from the SWAMI chassis. 
But, no other details on the requirements or procedures for battery movement or recharging were available so it was assumed that no other mechanical material handling equipment was available, but that it may be required.

Actions needed to reduce these potential hazards to an acceptable level involve implementing safe design, operation, and maintenance requirements. As corrective actions are implemented to preclude each cut set from occurring, the rate of the top event will decrease. For example, providing all necessary lifting devices for the battery during maintenance and recharging would reduce the rate of the top event from 5.53E-03 events per hour down to 0.53 events per hour, a risk reduction of 90\%. These requirements are listed starting on page 20.

\section{Cut Sets}

Cut sets with frequencies less than 1E-06 per hour are considered incredible per TABLE I - Risk Categories on page 6 and are acceptable without corrective action. There are 8 cut sets with event rates greater than $1 E-D f$ per hour. These cut sets and their frequencies are listed in TABLE II below. Since these cut sets occur at an unacceptable frequency per TABLE I, the hazards comprising thie events in these 8 cut sets should be eliminated or controlled to an acceptable level.

The FTA shows that when the top 8 cut sets are prevented from occurring through the implementation of the requirements starting on page 20, the rate of the top event will be reduced from 5.53E-03 events/hour down to less than $1 \mathrm{E}-06$ events/hour -- a decrease of over $99 \%$.

The FTA also proves that the rate of death/serious injury events due to the SWAMI contacting personnel (as opposed to objects) is clearly at an "Incredible" frequency (1.39E-15 events/hr) per TABLE I on page 6. The FTA predicts the SWAMI collision avoidance system to fail at the rate of 3.21E-09 events/hr largely due to the redundant collision avoidance systems. In fact, the risk of death/serious injury during operations from any causes is "Extremely Unlikely" (2.01 E-06 events/hr). The FTA also shows that more than $99 \%$ of the safety risk occurs during maintenance. The top two cut sets for SWAMI operation are movement of nearby equipment (overhead doors and cranes) due to activation by the SWAMI RF signal.

\section{SAFETY REQUIREMENTS}

\section{Introduction}

There are four basic categories of safety requirements pertinent to AMRs:

$\begin{array}{ll}\text { - } & \text { System Specification } \\ \text { - } & \text { Robot Specification } \\ \text { - } & \text { Procedures } \\ & \text { Training }\end{array}$


TABLE II Cut Sets

-

\begin{tabular}{|c|c|c|c|c|}
\hline $\begin{array}{c}\text { Cut } \\
\text { Set } \\
\#\end{array}$ & $\begin{array}{c}\text { Basic } \\
\text { Event } \\
\#\end{array}$ & Basic Event Description & $\begin{array}{l}\text { Basic } \\
\text { Event } \\
\text { Frequency }\end{array}$ & $\begin{array}{l}\text { Cut Set } \\
\text { Frequency }\end{array}$ \\
\hline \multirow[t]{2}{*}{1} & $\mathrm{~B} 25$ & $\begin{array}{l}\text { Battery needs to be removed for } \\
\text { maintenance }\end{array}$ & $1.00 E-02$ & $5.00 \mathrm{E}-03$ \\
\hline & II & $\begin{array}{l}\text { Battery manually handled/injury } \\
\text { occurs }\end{array}$ & $5.00 \mathrm{E}-01$ & \\
\hline \multirow[t]{2}{*}{2} & $\mathrm{~B} 1$ & SW'AMI not grounded - human error & $1.00 \mathrm{E}-03$ & 5.COE-04 \\
\hline & $\mathrm{B} 6 \mathrm{~A}$ & $\begin{array}{l}\text { Exposure to high voltage circuitry } \\
\text { during maintenace }\end{array}$ & $5.00 \mathrm{E}-01$ & \\
\hline 3 & B28 & $\begin{array}{l}\text { Short circuit in electrical system } \\
\text { causes fire }\end{array}$ & $1.00 E-05$ & $1.00 \mathrm{E}-05$ \\
\hline 4 & B27 & $\begin{array}{l}\text { Overheated CPU/electrical part causes } \\
\text { fire }\end{array}$ & $1.00 \mathrm{E}-05$ & $1.00 \mathrm{E}-05$ \\
\hline \multirow[t]{2}{*}{5} & B2 & Ground connection fails & $1.00 \mathrm{E}-05$ & $5.00 \mathrm{E}-06$ \\
\hline & B6A & $\begin{array}{l}\text { Exposure to high voltage circuitry } \\
\text { during maintenance }\end{array}$ & $5.00 \mathrm{E}-01$ & \\
\hline \multirow[t]{2}{*}{6} & B51 & $\begin{array}{l}\text { SWAMI RF signal moves overhead } \\
\text { door }\end{array}$ & $1.00 \mathrm{E}-05$ & $1.00 E-06$ \\
\hline & B52 & $\begin{array}{l}\text { Person in area of equipment } \\
\text { movement }\end{array}$ & $1.00 \mathrm{E}-01$ & \\
\hline \multirow[t]{2}{*}{7} & $\mathrm{~B} 50$ & SWAMI RF signal moves crane & $1.00 \mathrm{E}-05$ & $1.00 \mathrm{E}-06$ \\
\hline & B52 & $\begin{array}{l}\text { Person in area of equipment } \\
\text { movement }\end{array}$ & $1.00 E-01$ & \\
\hline \multirow[t]{3}{*}{8} & $\mathrm{~B} 21$ & Ignition source present & $1.00 E-01$ & $1.00 \mathrm{E}-06$ \\
\hline & $\mathrm{B} 22$ & Person in recharging area & $1.00 \mathrm{E}-01$ & \\
\hline & $\mathrm{B} 23$ & $\begin{array}{l}\text { Combustible hydrogen atmosphere } \\
\text { during recharging }\end{array}$ & $1.00 \mathrm{E}-04$ & \\
\hline
\end{tabular}

These 8 Cut Sets define the unacceptable SWAMI hazards identified in the FTA. 
These requirements are intended to prevent accidents from three principle conditions: Non-standard situations, human errors, and product failures. Safety requirements for the SWAMI are derived from three sources for this analysis:

- The Fault Tree Analysis

- The System Safety Hazard Analysis

- Applicable industry standards

National consensus standards, such as the American National Standards Institute, the National Fire Protection Association, the Occupational Safety and Health Act standards, and the National Electrical Code are used to derive safety requirements for AMRs and the SWAMI. Other guidance is taken from international standards listed in Safety in the Use of Industrial Robots. ${ }^{(34)}$ The requirements from these sources which are applicable to the SWAMI design, operation, and maintenance are listed below.

ANSI/RIA R15.06 Industrial Robots and Robot Systems - Safety Requirements

Although ANSI/RIA R15.06 explicitly excludes mobile robots from its scope, there are several safety recommendations in the standard which are applicable to the SWAMI and other mobile robots, and it would be prudent to consider their implementation in these systems. The paragraph number reference after each requirement below refers to an ANSI/RIA R15.06 paragraph. The applicable requirements are:

- Isolate sources of energy with lockout/tagout capability (para. 4.2.3).

- Use shields, filters, suppression and grounding to prevent hazardous motion due to Electromagnetic Interference (EMI), Radio Frequency Interference, and Electrostatic discharge (para. 4.2.5).

- Design the emergency stop using hardware-based components which override all other robot controls (para 4.5.1).

- $\quad$ Provide for lifting the robot (para. 4.10).

- Prevent mismating of connectors, using methods such as keying or labeling, which could cause a hazard if mismated (para. 4.11). Check signal integrity with self-diagnostics.

- Design so the loss of electrical power will not result in a hazard (para. 4.13).

- Design and construct so single point failures will not create a hazard (para. 4.14) or prevent the normal stopping action of the robot (para. 6.3.1.2).

- Evaluate environmental conditions to ensure robot compatibility with operating conditions, like dust, corrosive conditions, humidity and temperature (para. 5.8).

- Failure of a single component of presence-sensing devices shall not prevent the normal stopping action of the robot (para. 6.3.2.1).

- Use audible or visual warning signals to warn of the robot (para. 6.4.3). 


\section{ANSI B56.5 Automated Guided Vehicles (AGV)}

Since the SWAMI is actually an Autonomous Mobile Robot (AMR) and not an AGV, this standard is not directly applicable to the SWAMI. However, the standard does present several safety recommendations which would eliminate or control hazards of SWAMI operation and maintenance. Safety requirements applicable to the SWAMI and other AMRs from ANSI B56.5 which have not already been mentioned above are:

- Keep floors dry and free of oil, grease, or other residue, and keep the floors well maintained so they are not rough. Wet or slippery floors will affect turning and stopping distances. The tractive force of the vehicle becomes unpredictable, and bumper range and stopping distance are significantly greater than the vehicle design values. Rough floors will also cause excessive vibration and induce failures.

- Bumpers must directly control motive power interrupts and must not require software or hardware logic or signal conditioning (such as amplifiers or inverters) for operation. Bumper acivation signals may be monitored by processing circuitry for diagnostics. The bumper stop circuit must activate at a maximum force of $8 \mathrm{lb}$ parallel to the floor.

- Loss of guidance or path detection must render the vehicle motionless.

- Overspeed detection is required.

- Microprocessors must have a software lockup detection circuit. Loss of the trigger pulse, typically caused by computer hardware failures, must stop the vehicle.

- Label battery changing and charging areas according Paragraph 5.3 of NFPA 505 to prevent ignition of explosive vapors. ${ }^{(35)}$

- Paint highly reflective surfaces with nonreflecting paint to prevent blinding of the laser collision avoidance system.

- Train operating personnel and enforce operating rules.

- Establish and monitor maintenance programs, including preventive maintenance.

- Post warning signs at the tacility to alert personnel of the robot's operation.

- Identify all radiated emissions, either elctromagnetic or optical energy, that could adversely affect the vehicle's operation or other nearby operations.

- Deviation of travel from the intended path by more than six inches when using internal reference shall constitute an emergency stop condition.

- Any loss of speed control shall cause an emergency stop.

- The vehicle must be able to be stopped at rated speed, $3 \mathrm{mi} / \mathrm{hr}$, between object sensing and contact with the frame.

- Provide low battery indication.

- Activation of the emergency stop must require manual intervention to return the vehicle to normal operating conditions.

- The maximum grade for ramp operation must be labeled on the vehicle in letters at least 1.5 inches high. The SWAMII must also have a "CAUTION - AUTOMATIC VEHICLE" label. The facilities should have signs posted outside warning of the robot's autonomous operation. 


\section{International Labour Organization}

The following robot safety requirements are a compilation of international standards. Robot safety requirements were researched for several countries, including France, the German Democratic Republic, the Federal Republic of Germany, Japan, the former USSR, and the United Kingdom. ${ }^{(34)}$ The requirements from these sources applicable to the SWAMI and other AMRs which have not been mentioned previously are listed below.

- Fire protection, particularly of the control system, should include a chassis temperature sensor and a thermal power cut-off.

- The actuating circuit for any electrically operated stop should be independent of the control program.

- Check safeguarding subsystems before applying power to the robot.

- Software programs providing specific satety interlocks should not be able to be violated, preferably by being stored in read-only memory.

\section{Fault Tree Analysis}

The safety requirements listed below will controi the cut sets identified in the Fault Tree Analysis from materializing and keep the potential of all identified hazards below a frequency of one event per million hours.

- Provide a mechanical lifting device for moving the SWAMI battery during maintenance and recharging.

- Follow the National Electrical Code in electrical design, bonding and grounding (Article 250), capacitor bleed down (Article 460), and overcurrent protection (Article 240) to help control electrical hazards.

- Include guards, barriers, interlocks and warning labels in the SWAMI design to prevent personnel from accidently contacting high voltage during maintenance.

- Implement grounding instructions for high voltage circuits and capacitors, and a lockout/tagout system in maintenance procedures.

- Test the SWAMI at maximum operating conditions $\left(105^{\circ} \mathrm{F}\right.$ and $100 \%$ humidity) to verify the CPU or electrical system won't overheat. Prevent overheating with a temperature sensor and power cutoff if overheating is possible.

- Verify that SWAMI RF energy or EMI cannot operate nearby equipment.

- Prohibit ignition sources within 50 feet of battery recharging operations and provide ventilation in the recharging area to keep the potential hydrogen gas concentration below $25 \%$ of its Lower Explosive Limit.

- Design and construct the host computer for maximum reliability since it is a common mode failure for the four collision avoidance systems.

System Safety Hazard Analysis

The System Safety Hazard Analysis has identitied additional safety requirements unique 
to the SWAMI and other Autonomous Mobile Robots (AMR) which have not been formally specified in the aforementioned nationat standards or in the Fault Tree Analysis. These requirements are:

- For accurate range calculations by the ultrasonic range finder, install a temperature sensor on the robot and provide a temperature correction factor in the range algorithm. - Include verification of the transmitted ultrasonic pulse in the diagnostics to determine correct transmitter operation.

- Provide self-diagnostic capability for the entire tactile collision avoidance system on the SWAMI, including the tape switches. Design the tape switches to fail in the activated position to prevent loss of tactile sensing in the event of tape switch failure.

- Determine SWAMI's center of gravity and verify it cannot tip over, taking into consideration up and down ramp operation, sharp turns, and the forces generated from acceleration and emergency stops.

- Provide automatic indication to the base computer and operator if the facility fire extinguishing system activates to prevent SWAMI from getting contaminated with water.

- Protect SWAMI from toxic chemical, radioactively contaminated, and corrosive air environments with positive pressure ventilation and enclosures.

- Implement procedures to prohibit rapid movement of the SWAMI from a hot to a cold environment to prevent condensation and damage to safety-critical electrical and software subsystems.

- Include procedures for possible deactivation of the SWAMI in the event of severe electrical storms, in case electrical interference prevents activation of safety systems.

- Make provisions for decontaminating the SWAMI from both chemical and radiological contamination using methods which would not damage its equipment or software.

- Determine the drive torque in the SWAMI drive wheels and verify that this torque is insufficient to push over a storage drum.

- Label the robot and facilities cautioning personnel not to stare at the laser beam.

\section{CONCLUSIONS}

The Fault Tree Analysis (FTA) identified 8 cut sets which could lead to the Top Event of "Serious injury or death during SWAMI Operation or Maintenance" at an unacceptable frequency (more frequent than one event per million operating hours). Actions to prevent these events from occurring were identified and listed on page 20. If these actions are implemented the rate of potential death/serious injury events will be reduced from 5.53E-03 events/hr down to less than $1 \mathrm{E}-06$ events $/ \mathrm{hr}$, a risk reduction of over $99 \%$ and an acceptable risk per this analysis. The FTA shows that the risk of death/serious injury during SWAMI operation is extremely inlikely. Movement of nearby equipment due to SWAMI RF energy and overheating of the CPU/electrical system are the only unacceptable operational safety risks. More than $99 \%$ of the safety risk occurs during maintenance.

The System Safety Hazard Analysis identified other safety hazards specifically applicable to the SWAMI and generally applicable to other AMRs. Safety requirements were derived to eliminate or control these hazards. This analysis also identified hazards unique to the application 
of SWAMI in hazardous toxic chemical and radioactive environments. Safety requirements addressing these hazards are listed on pages $20-21$.

No national standards exist which are directly applicable to the design, construction, operation and maintenance of Autonomous Mobile Robots (AMR) like the SWAMI. ANSI/RIA R15.06 does not apply to mobile robots, and ANSI B56.5 is intended for Autonomous Guided Vehicles only. There are national standards which address specific system hazards, however, such as the National Electrical Code, the National Fire Protection Association, and the Occupational Safety \& Health Act standards. It is important that these standards be implemented in the SWAMI system design, operation and maintenance. Standards from the International Labour Organization also provide guidance on other AMR safety standards. A set of safety requirements were derived from these sources and are found on pages $18-20$.

This analysis primarily addresses design safety of AMRs since safety through design is the most effective method to ensure safety. However, training and procedures are also important measures in increasing the safety of personnel.

\section{RECOMMENDATIONS}

Implement the safety recommendations derived from the Fault Tree Analysis to keep the risk of death/serious injury from SWAMI operation and maintenance below one event per million hours.

Verify that the safety requirements derived from the analyses and applicable industry standards are complied with in order to protect personnel and prevent damage to the SWAMI and other autonomous mobile robots.

Further research should be conducted addressing the effectiveness of ultrasonic collision avoidance systems and vision systems for use in autonomous mobile robots.

\section{REFERENCES}

1. Robotics for Mixed Waste Operations Demonstration. November $2-4$, 1993. Robotics Technology Development Program, DOE ER/WM, Office of Technology Development.

2. Resource Conservation and Recovery Act, Title 40, Code of Federal Regulations, Chapter I - EPA, Subchapter J - Superfund, Emergency Planning \& Community Right-To-Know Programs, Part 264 - Standards for Owners and Operators of Hazardous Waste Treatment, Storage and Disposal Facilities (1984), 42 U.S.C.A. $\S 6901$ to 6992.

3. Ohio Administrative Code (OAC), OAC 3745-66-74, Inspections (1981).

4. Footprint for Nuclear Inventory. FERMCO, March 31, 1993.

5. Hazen, F. Brack: The SWAMI Container Inspection Robot: Fernald Site Requirements. September 28, 1993.

6. Bartos, Ronald J.: Mobile Robotic Inspection of Hazardous Materials. Feasibility Study for Robotics I, University of Cincinnati. November 18, 1993. 
7. Comprehensive Environmental Response, Compensation and Liability Act, Title 40, Code of Federal Regulations, Chapter I -EPA, Subchapter J - Superfund, Emergency Planning \& Community Right-To-Know Programs, Part 300 (1980).

42 U.S.C.A. $\S \S 9601$ to 9675 . Amended by Superfund Amendments \& Reauthorization Act of 1986, PL 99-499.

8. Vlahakis, Dino: A Design and Simulation of an Automated Drum Management System. MS Thesis. University of Cincinnati. 1993.

9. American National Standards Institute/Robotic Industries Association: R15.06, Industrial Robots and Robot Systems - Safety Requirements. August 19, 1992.

10. International Organization for Standardization: ISO/DP 10218, Manipulating Industrial Robots - Safery. Geneva (1989).

11. Roberts, N. H., et. al.: Fault Tree Handbook, NUREG-0492, U. S. Nuclear Regulatory Commission. Washington, D.C. January 1981.

12. Rasmussen, N. C.: WASH-1400, Reactor Safety Study: An Assessment of Accident Risks in U. S. Commercial Nuclear Power Plants, Appendixes 3 \& 4: Failure Data. U. S. Nuclear Regulatory Commission. October 1975.

13. United States Department of Defense: MIL-HDBK-217F, Reliability Prediction of Electronic Equipment, Notice 1. July 10, 1992.

14. Department of Energy: DOE-STD-3005, Evaluation Guidelines for Accident Analysis and Safety Structures, Systems, and Components. February 25, 1994.

15. Hall, Ernest L., et. al.: Assessment of the State of the Art for Self-Guided Vehicles. Contract FERMCO 2-15526. September 1993.

16. King, Steven J. and Carl F. R. Weiman: HelpMate ${ }^{\text {Th }}$ Autonomous Mobile Robot Navigation System. Sociery of Photo-Optical Instrumentation Engineers (SPIE) Proceedings, Mobile Robots V 1388:190-197 (1990).

17. Ghayalod, Manoj P. and Ernest L. Hall: Mobile Robot Design for Safety. Eleventh International System Safety Conference, Cincinnati. August 2, 1993.

18. Hazen, F. Brack: Robotics at Fernald Safety Meeting Briefing. September 2, 1993.

19. Borenstein. Johann and Yoram Koren: Histogramic in-motion mapping for mobile robot obstacle avoidance. IEEE Tranactions on Robotics and Automation 7:535539 (1991).

20. Everett. H. R. and A. M. Flynn: A Programmable Near-Infrared Proximity Detector for Robot Navigation. Procecdings of the International Society for Optical Engineering, Mobile Robots 727:221-230 (1986).

21. Lasecki, Robert R.: Safety of Automated Guided Vehicles. Proceedings of the SME Automated Guided Vehicle Conference (1986).

22. Cox, Ingemar J.: Blanche -- an experiment in guidance and navigation of an autonomous robot vehicle. IEEE Transactions on Robotics and Automation 7:193-204 (1991).

23. Berni. Gerardo and Susan Hackwood, editors: Recent Advances in Robotics. pp. 320408. John Wiley \& Sons (1985).

24. Cox, I. J. and G. T. Wilfong, editors: Autonomous Robot Vehicles. pp. 454-455. Springer-Verlag, New York (1990). 
25. Bolz, Ray E. and George L. Tuve, editors: CRC Handbook of Tables for Applied Engineering Science, 2nd Edition: p. 9. CRC Press, Inc., Boca Raton (1970).

26. Sugimoto, Noboru and Kunitomo Kauguchi: Fault Tree Analysis of Hazards Created by Robots. Thirtcenth International Symposium on Industrial Robots 7 1:9-13 to 9-28. Robotics International of SME (1983).

27. Graham, James H.: Safety, reliability, and human factors in robotic systems. pp. 78, 79, 93. Van Nostrand Reinhold, New York (1991).

28. American National Standards Institute: ANSI Z136.1 - 1986, Safe Use of Lasers. New York (1986).

29. Bartos, R. J.: Memo: Telephone conversations with Paul Cappa and Steve King, TRC. April 12 and April 15, 1994.

30. Lasecki, R. R.: Proposed ANSI B56.5 Review. Proceedings of the Fourth International Conference on Automated Guided Vehicle Systems. pp. 75-85. June 1986.

31. Tracey, P. M.: AGV System Safety - New Developments to Meet Changing Needs. Automated Guided Vehicle Systems. R. H. Hollier, editor. pp. 43-50. IFS Publications Ltd, UK (1987).

32. National Fire Protection Association (NFPA). National Electrical Code (NFPA 70). NFPA, Quincy, MA (1993).

33. United States Department of Defense, Department of the Army: $M I L-H D B K-759 A$, Human Factors Enginecring Design for Army Materiel. June 30, 1981.

34. International Labour Organization. Safery in the Use of Industrial Robots. pp. 24-45, 55. Geneva (1989).

35. NFPA: NFPA 505 Powered Industrial Trucks. NFPA, Quincy, MA (1992).

\section{ADDITIONAL READING}

1. Lee, Jay, editor: Robors in Inspecrion. Society of Manufacturing Engineers. Dearborn MI (1987).

2. Miller, Richard K., editor: Automated Guided Vehicles and Automated Manufacturing. pp. 89-96. Society of Manufacturing Engineers, Dearborn MI (1987).

3. Kumamoto, Hiromitsu, Yoshinobu Sato and Koichi Inoue: Hazard Identification and Safety Assessment of Human-Robot Systems. Engineering Risk and Hazard Assessment, Volume I, Abraham Kandel and Eitan Avni, editors. pp. 72-73. CRC Press, Inc., Boca Raton (1988).

4. Weber, David M.: Treat 'em with Respect, says Robot Standard. Electronics Week 57:34-35 (1984).

5. Rahimi. Mansour and Waldemar Karwowski, editors: Human-robot Interaction. Taylor \& Francis, London (1992).

6. Bonney, Maurice C.and Y. F. Yong, editors: Robot Safety. Bedford, Berlin (1985). 


\section{SWAMI II SSHA}

\begin{tabular}{|c|c|c|c|c|}
\hline $\begin{array}{l}\text { ID } \\
\#\end{array}$ & IIAZARD & CAUSE & EFFECTS & $\begin{array}{l}\text { CORRECTIVE } \\
\text { ACTION } \\
\end{array}$ \\
\hline 1 & Robot tips over & $\begin{array}{l}\text { Robot is top-heavy, } \\
\text { operation on ramp, } \\
\text { accel/decel forces }\end{array}$ & $\begin{array}{l}\text { 1. Major damage to robot } \\
\text { 2. Damage to waste drums } \\
\text { 3. Personnel injury }\end{array}$ & $\begin{array}{l}\text { 1. Locate robot's } \\
\text { center of } \\
\text { gravity to verify it } \\
\text { can't tip over in any } \\
\text { operational scenario } \\
\text { 2. Label robot for } \\
\text { maximum ramp } \\
\text { operation }\end{array}$ \\
\hline 2 & $\begin{array}{l}\text { Person struck by } \\
\text { robot during } \\
\text { inspection }\end{array}$ & $\begin{array}{l}\text { SWAMI collision avoidance system } \\
\text { fails and person in robot inspection } \\
\text { area }\end{array}$ & $\begin{array}{l}\text { 1. Personnel injury } \\
\text { 2. Major robot damage }\end{array}$ & $\begin{array}{l}\text { 1. Post warnings } \\
\text { outside robot inspection } \\
\text { area } \\
\text { 2. Robot obstacle } \\
\text { avoidance systems }\end{array}$ \\
\hline 3 & $\begin{array}{l}\text { Robot strikes } \\
\text { objects }\end{array}$ & $\begin{array}{l}\text { Failure of path program, ultrasound } \\
\text { sensors, laser, tactile sensors }\end{array}$ & Damage to robot & $\begin{array}{l}\text { Several redundant } \\
\text { obstacle avoidance } \\
\text { systems }\end{array}$ \\
\hline 4 & $\begin{array}{l}\text { Drum leakage } \\
\text { onto robot }\end{array}$ & Robot close to leaking drum & $\begin{array}{l}\text { 1. Robot contamination } \\
\text { 2. Electrical system damage }\end{array}$ & $\begin{array}{l}\text { Pre-inspection of aisles } \\
\text { to locate leaks }\end{array}$ \\
\hline 5 & $\begin{array}{l}\text { Loss of auto } \\
\text { speed control }\end{array}$ & $\begin{array}{l}\text { Robot rolls down incline out of } \\
\text { control }\end{array}$ & $\begin{array}{l}\text { 1. Robot damage } \\
\text { 2. Damage to nearby } \\
\text { objects/personnel }\end{array}$ & $\begin{array}{l}\text { Include mechanical } \\
\text { devices to slowly stop } \\
\text { motion if control lost }\end{array}$ \\
\hline
\end{tabular}




\section{SWAMI II SSHA}

\begin{tabular}{|c|c|c|c|c|}
\hline ID & HAZARD & CAUSE & EFFECTS & $\begin{array}{l}\text { CORRECTIVE } \\
\text { ACTION } \\
\end{array}$ \\
\hline 6 & $\begin{array}{l}\text { Automatic facility } \\
\text { fire extinguishing } \\
\text { system activates }\end{array}$ & $\begin{array}{l}\text { Actual or false extinguishing system } \\
\text { activation }\end{array}$ & Major robot damage & $\begin{array}{l}\text { Fire =larm system } \\
\text { interlock to base } \\
\text { computer }\end{array}$ \\
\hline 7 & $\begin{array}{l}\text { Failure of } \\
\text { obstacle } \\
\text { avoidance system }\end{array}$ & Electrical failure, software failure & $\begin{array}{l}\text { Robot strikes objects or } \\
\text { personnel }\end{array}$ & $\begin{array}{l}\text { 1. Self diagnostics } \\
\text { during operation } \\
\text { 2. Stop robot until } \\
\text { operator intervenes }\end{array}$ \\
\hline 8 & $\begin{array}{l}\text { Dust or other } \\
\text { contaminant gets } \\
\text { inside robot }\end{array}$ & $\begin{array}{l}\text { Dust in facility, inadequate integrity } \\
\text { of robot housing }\end{array}$ & $\begin{array}{l}\text { Contamination of electrical } \\
\text { system or CPU }\end{array}$ & $\begin{array}{l}\text { Adequate closure of } \\
\text { robot housing, } \\
\text { positive pressure } \\
\text { ventilation }\end{array}$ \\
\hline 9 & Slippery floor & Leaking drums, pipes, roof & $\begin{array}{l}\text { Diminished steering accuracy, } \\
\text { poor stopping accuracy, } \\
\text { collisions }\end{array}$ & Floor maintenance \\
\hline 10 & Rough floor & $\begin{array}{l}\text { Poor maintenance, degradation, } \\
\text { corrosion }\end{array}$ & $\begin{array}{l}\text { Excessive vibration, induced } \\
\text { failures }\end{array}$ & $\begin{array}{l}\text { Proper maintenance } \\
\text { and upkeep of floors }\end{array}$ \\
\hline 11 & Software lockup & Microprocessor SW or HW failure & Collision & $\begin{array}{l}\text { Software lockup } \\
\text { detection circuit } \\
\text { (watchdog timer) }\end{array}$ \\
\hline
\end{tabular}




\section{SWAMI II SSHA}

\begin{tabular}{|c|c|c|c|c|}
\hline $\begin{array}{l}\text { ID } \\
\#\end{array}$ & HAZARD & CAUSE & EFFECTS & $\begin{array}{l}\text { CORRECTIVE } \\
\text { ACTION } \\
\end{array}$ \\
\hline 12 & $\begin{array}{l}\text { Explosive } \\
\text { hydrogen gas } \\
\text { accumulation }\end{array}$ & Battery charging & Explosion & $\begin{array}{l}\text { Proper ventilation, no } \\
\text { ignition sources, } \\
\text { warning signs per } \\
\text { NFPA } 505\end{array}$ \\
\hline 13 & $\begin{array}{l}\text { I aser optics } \\
\text { biinded }\end{array}$ & $\begin{array}{l}\text { Sudden exposure to strong sunlight; } \\
\text { highly reflective surfaces }\end{array}$ & $\begin{array}{l}\text { False optical signals, loss of } \\
\text { optical collision avoidance }\end{array}$ & $\begin{array}{l}\text { Priority software in } \\
\text { collision avoidance; } \\
\text { nonreflective paint }\end{array}$ \\
\hline 14 & $\begin{array}{l}\text { False ultrasonic } \\
\text { sensing signal }\end{array}$ & $\begin{array}{l}\text { Target size and shape; ambient } \\
\text { noise; induced noise from vibration }\end{array}$ & $\begin{array}{l}\text { Loss of ultrasonic collision } \\
\text { avoidance }\end{array}$ & $\begin{array}{l}\text { Redundant collision } \\
\text { avoidance systems }\end{array}$ \\
\hline 15 & Electrical shock & $\begin{array}{l}\text { 1. Personnel exposure to high } \\
\text { voltage } \\
\text { circuits during maintenance } \\
\text { 2. Stored voltage in capacitors }\end{array}$ & Serious injury or death & $\begin{array}{l}\text { 1. NEC Stds for } \\
\text { grounding, bonding, } \\
\text { overcurrent protection } \\
\text { 2. Bleed-off resistors } \\
\text { for capacitors } \\
\text { 3. Training \& } \\
\text { certification for maint } \\
\text { personnel }\end{array}$ \\
\hline 16 & $\begin{array}{l}\text { Corrosion of } \\
\text { parts }\end{array}$ & $\begin{array}{l}\text { Dissimilar metals; exposure to harsh } \\
\text { environments }\end{array}$ & $\begin{array}{l}\text { Material fatigue, electrical } \\
\text { failures }\end{array}$ & $\begin{array}{l}\text { Use compatible } \\
\text { materials in assembly; } \\
\text { protect from corrosive } \\
\text { environments }\end{array}$ \\
\hline
\end{tabular}




\section{SWAMI II SSHA}

\begin{tabular}{|c|c|c|c|c|}
\hline $\begin{array}{l}\text { ID } \\
\#\end{array}$ & IIAZARD & CAUSE & EFFECTS & $\begin{array}{l}\text { CORRECTIVE } \\
\text { ACTION } \\
\end{array}$ \\
\hline 17 & $\begin{array}{l}\text { Condensation } \\
\text { inside robot } \\
\text { housing }\end{array}$ & $\begin{array}{l}\text { Moving from cold (outside winter } \\
\text { temperature) to hot environment } \\
\text { (inside building for maintenance) }\end{array}$ & $\begin{array}{l}\text { Electrical failures, computer } \\
\text { disk failures }\end{array}$ & $\begin{array}{l}\text { Procedures prohibiting } \\
\text { rapid changes in } \\
\text { environment }\end{array}$ \\
\hline 18 & $\begin{array}{l}\text { Loss of RF or } \\
\text { Ethernet } \\
\text { communication } \\
\text { signal between } \\
\text { remote base and } \\
\text { onboard } \\
\text { computers }\end{array}$ & EMI, lightning storm & $\begin{array}{l}\text { Loss of SWAMI location by } \\
\text { operator }\end{array}$ & $\begin{array}{l}\text { 1.EMI-protected } \\
\text { circuits } \\
\text { 2.Procedures during } \\
\text { storms }\end{array}$ \\
\hline 19 & $\begin{array}{l}\text { SWAMI CPU } \\
\text { overheats and } \\
\text { shuts down }\end{array}$ & $\begin{array}{l}\text { Inadequate ventilation, operation at } \\
1(10)^{\circ} \mathrm{F}\end{array}$ & $\begin{array}{l}\text { Lack of collision avoidance } \\
\text { systems, damage to robot, } \\
\text { person struck }\end{array}$ & $\begin{array}{l}\text { Monitor CPU housing, } \\
\text { provide ventilation, } \\
\text { test heat output of } \mathrm{CPU} \\
\text { at } 100^{\circ} \mathrm{F}\end{array}$ \\
\hline 20 & $\begin{array}{l}\text { Manual lifting of } \\
\text { heavy battery } \\
(250 \text { \#) }\end{array}$ & Battery recharging or maintenance & $\begin{array}{l}\text { Personnel injury, battery } \\
\text { dropped and damaged }\end{array}$ & $\begin{array}{l}\text { Mechanical lifting } \\
\text { device for battery }\end{array}$ \\
\hline 21 & $\begin{array}{l}\text { SWAMI knocks } \\
\text { over } \operatorname{drum}(\mathrm{s})\end{array}$ & Collision avoidance systems fail & $\begin{array}{l}\text { Personnel injury, SWAMI } \\
\text { damage, contamination spread }\end{array}$ & $\begin{array}{l}\text { Verify SWAMI cannot } \\
\text { knock over drums }\end{array}$ \\
\hline
\end{tabular}




\section{SWAMI II SSHA}

\begin{tabular}{|c|c|c|c|c|}
\hline $\begin{array}{l}\text { ID } \\
\#\end{array}$ & HAZARD & CAUSE & EFFECTS & $\begin{array}{l}\text { CORRECTIVE } \\
\text { ACTION }\end{array}$ \\
\hline 22 & $\begin{array}{l}\text { Range distance } \\
\text { calculation } \\
\text { greater than } \\
\text { actual } \\
\end{array}$ & $\begin{array}{l}\text { Cold temperature decreases speed of } \\
\text { sound }\end{array}$ & Collision with object or person & $\begin{array}{l}\text { Temp sensor and temp } \\
\text { correction factor in } \\
\text { range algorithm }\end{array}$ \\
\hline 23 & $\begin{array}{l}\text { Tactile system } \\
\text { failure }\end{array}$ & $\begin{array}{l}\text { Tactile contact strips sensitive to } \\
\text { damage }\end{array}$ & Collision with object or person & $\begin{array}{l}\text { Diagnostics of } \\
\text { complete tactile circuit; } \\
\text { fail-actuated } \\
\text { tactile strips }\end{array}$ \\
\hline 24 & $\begin{array}{l}\text { Bumper system } \\
\text { collision } \\
\text { avoidance failure }\end{array}$ & $\begin{array}{l}\text { Force threshold too high }(>8 \#) \text {, } \\
\text { bumper travel too short }\end{array}$ & Collision with object or person & $\begin{array}{l}\text { Provide adequate } \\
\text { bumper travel for } \\
\text { reaction time; use } \\
\text { small enough force } \\
\text { threshold }\end{array}$ \\
\hline 25 & $\begin{array}{l}\text { Emergency stop } \\
\text { fails }\end{array}$ & $\begin{array}{l}\text { Emergency stop relies on SW, logic, } \\
\text { relays }\end{array}$ & Contact with person or object & $\begin{array}{l}\text { Emergency stop must } \\
\text { not rely on SW, logic, } \\
\text { or relays }\end{array}$ \\
\hline 26 & $\begin{array}{l}\text { Inadvertent } \\
\text { operation of } \\
\text { nearby equipment } \\
\text { by SWAMI }\end{array}$ & SWAMI RF or EAIl energy & $\begin{array}{l}\text { Personnel injury, equipment } \\
\text { damage }\end{array}$ & $\begin{array}{l}\text { Test SWAMI RF and } \\
\text { EMI for activation of } \\
\text { other equipment such } \\
\text { as overhead doors and } \\
\text { cranes }\end{array}$ \\
\hline
\end{tabular}




\section{SWAMI II SSHA}

\begin{tabular}{|c|c|c|c|c|}
\hline $\begin{array}{l}\text { ID } \\
\#\end{array}$ & HAZARD & CAUSE & EFFECTS & $\begin{array}{c}\text { CORRECTIVE } \\
\text { ACTION } \\
\end{array}$ \\
\hline 27 & $\begin{array}{l}\text { Laser energy } \\
\text { hazard to eyes of } \\
\text { personnel }\end{array}$ & Laser energy power & Severe personnel injury & $\begin{array}{l}\text { 1. Verify low power of } \\
\text { laser } \\
2 \text {. Post signs in } \\
\text { facilities and label } \\
\text { SWAMI to wam } \\
\text { personnel not to stare } \\
\text { at beam per ANSI } \\
\text { Z136.1. }\end{array}$ \\
\hline 28 & $\begin{array}{l}\text { Personnel unable } \\
\text { to access } \\
\text { emergency stop } \\
\text { buttons }\end{array}$ & $\begin{array}{l}\text { Tw'o emergency stop buttons on } \\
\text { HelpMate }{ }^{\text {Th }} \text { robot intended for } \\
\text { forward robot motion only. SWAMI } \\
\text { will move backwards. If SWAMI is } \\
\text { moving backwards and personnel } \\
\text { behind SWAMI need to activate } \\
\text { emergency stop button, they may not } \\
\text { be able to reach emergency buttons } \\
\text { in front. }\end{array}$ & $\begin{array}{l}\text { Collision with personnel if all } \\
\text { collision avoidance systems } \\
\text { fail. }\end{array}$ & $\begin{array}{l}\text { Provide additional } \\
\text { emergency stop } \\
\text { mechanisms which are } \\
\text { accessible from behind } \\
\text { the SWAMI. }\end{array}$ \\
\hline 29 & $\begin{array}{l}\text { SWAMI } \\
\text { contamination }\end{array}$ & Spill from drum & $\begin{array}{l}\text { Toxic chemical or radiological } \\
\text { contamination requiring } \\
\text { decontamination }\end{array}$ & $\begin{array}{l}\text { Develop } \\
\text { decontamination } \\
\text { procedures that don't } \\
\text { damage SWAMI }\end{array}$ \\
\hline
\end{tabular}




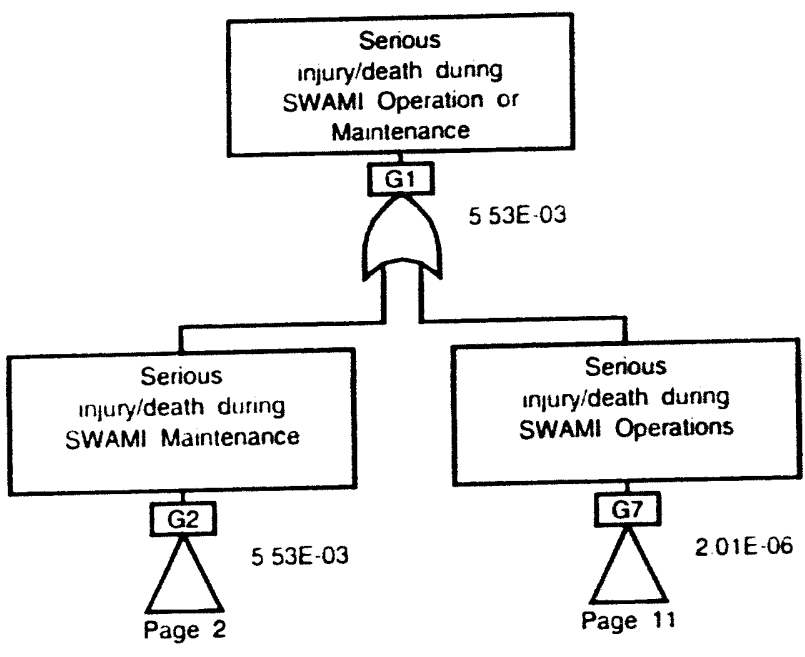




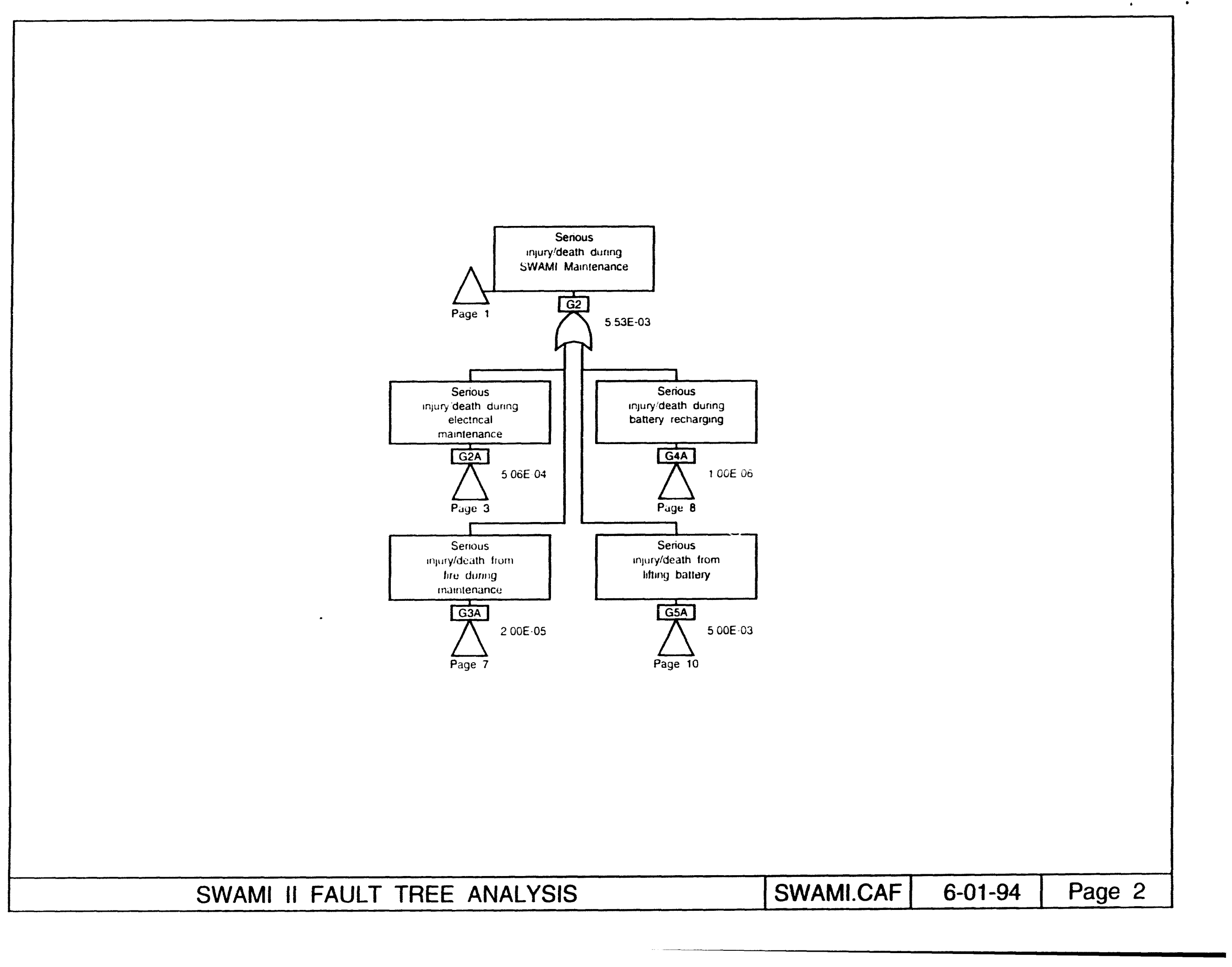




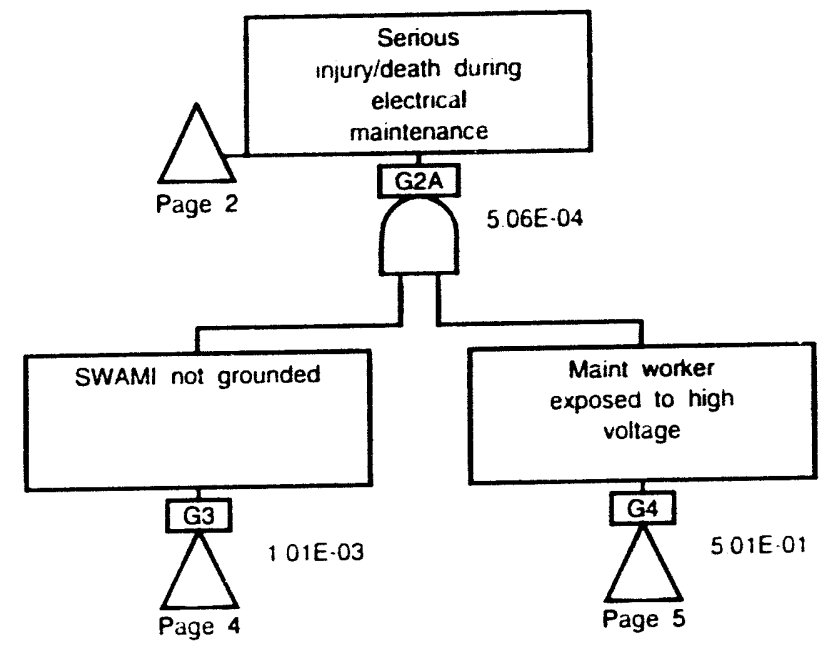




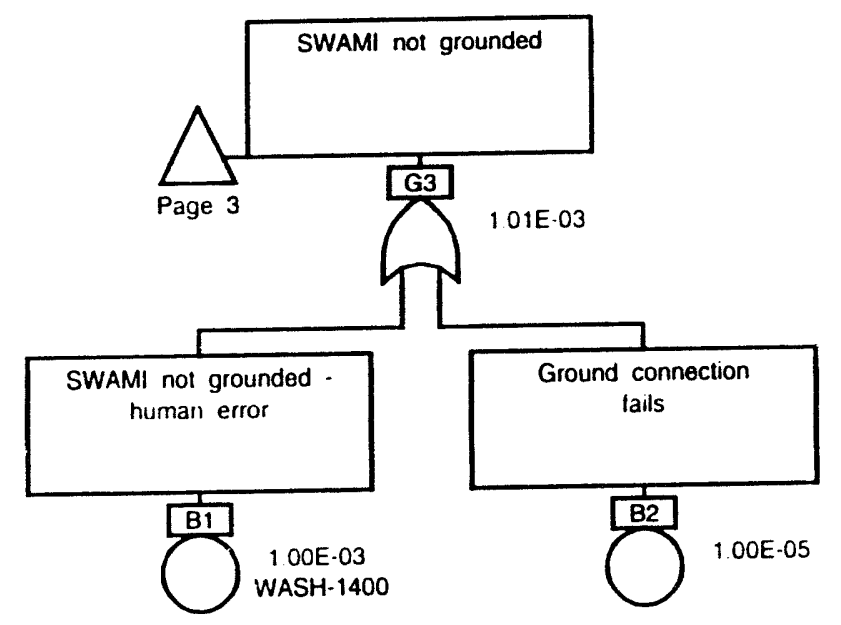




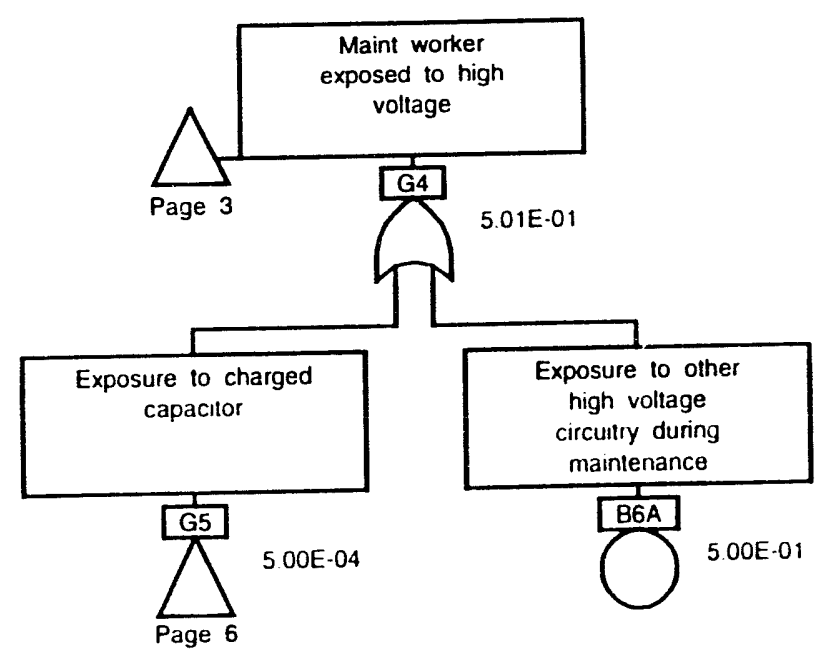




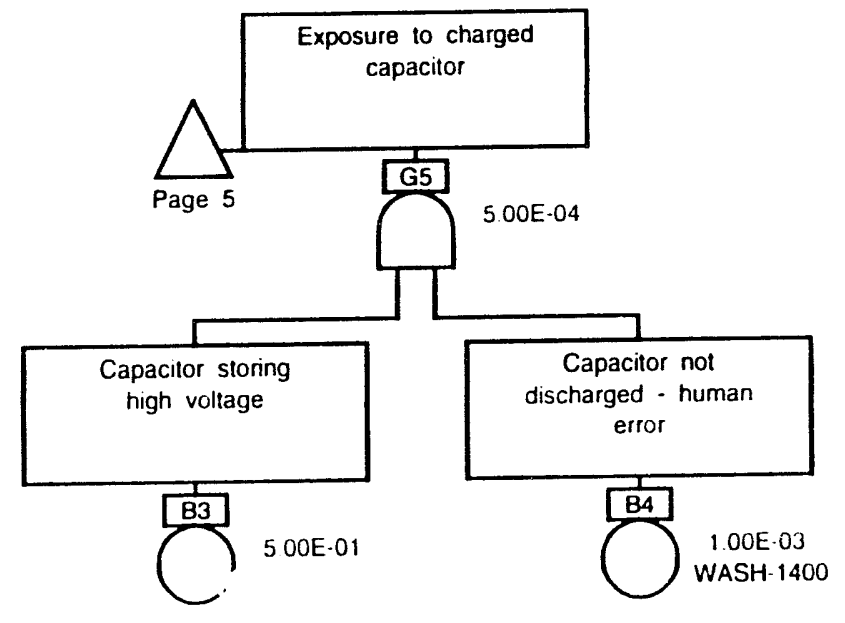




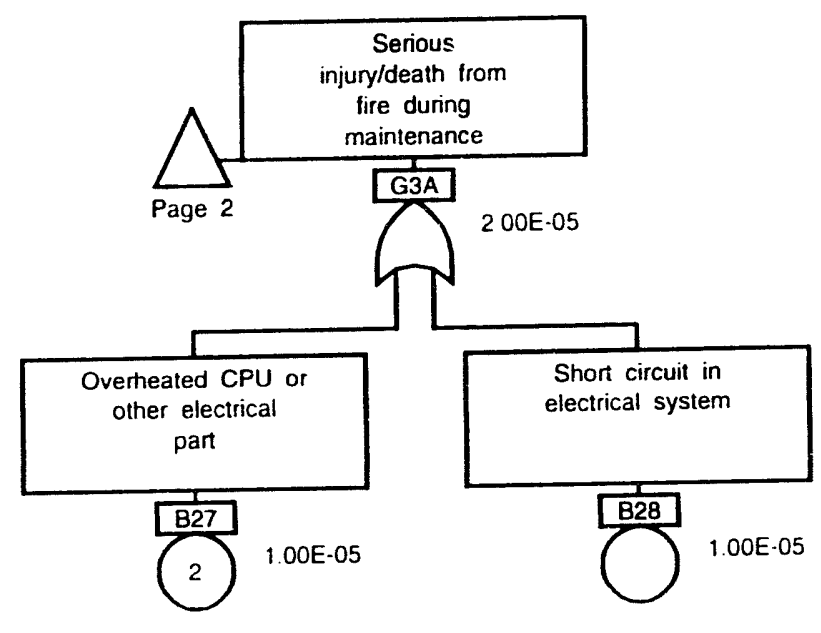




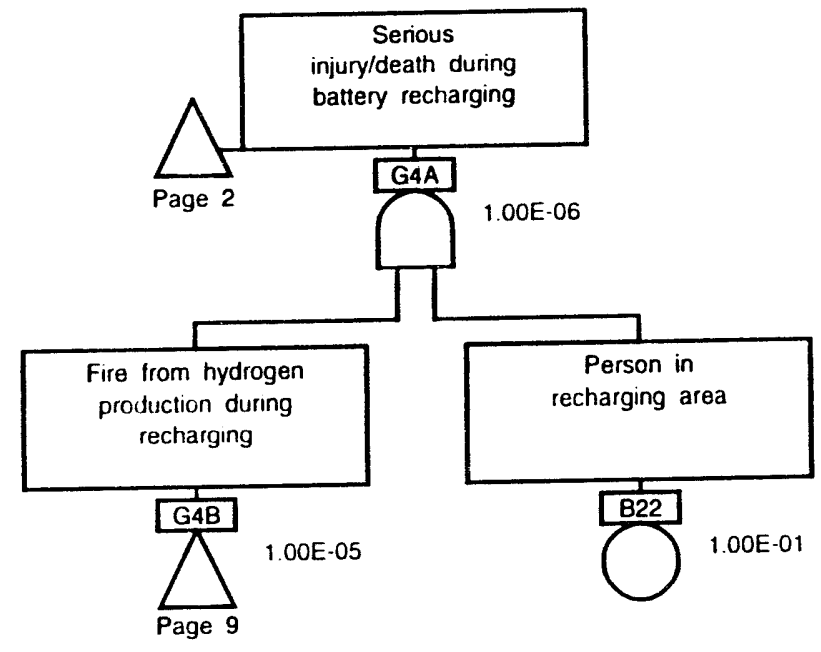




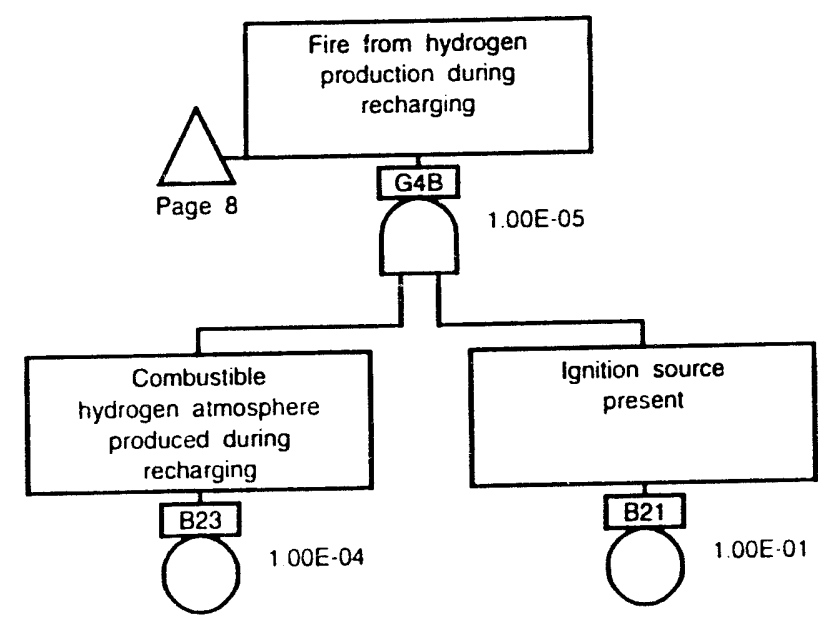




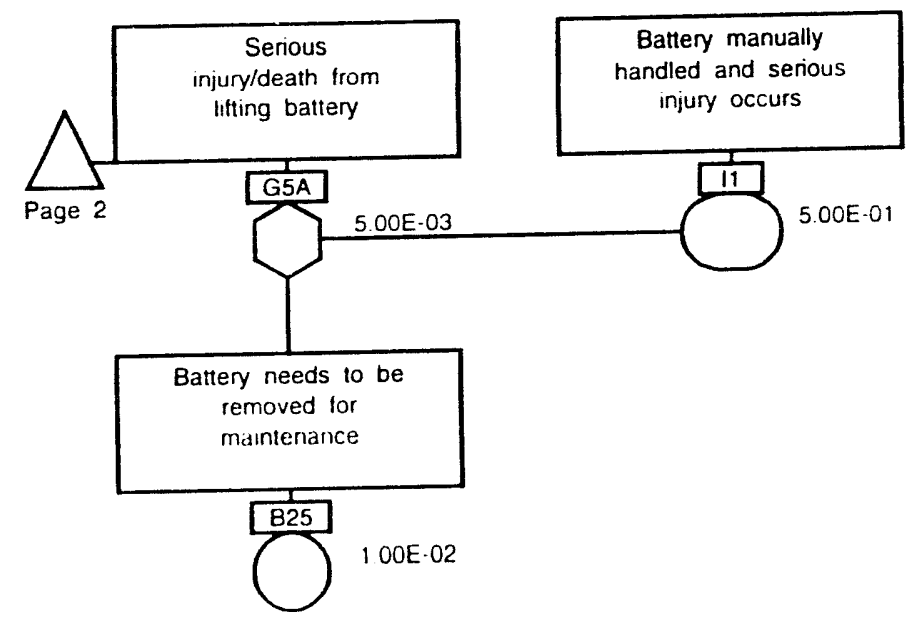




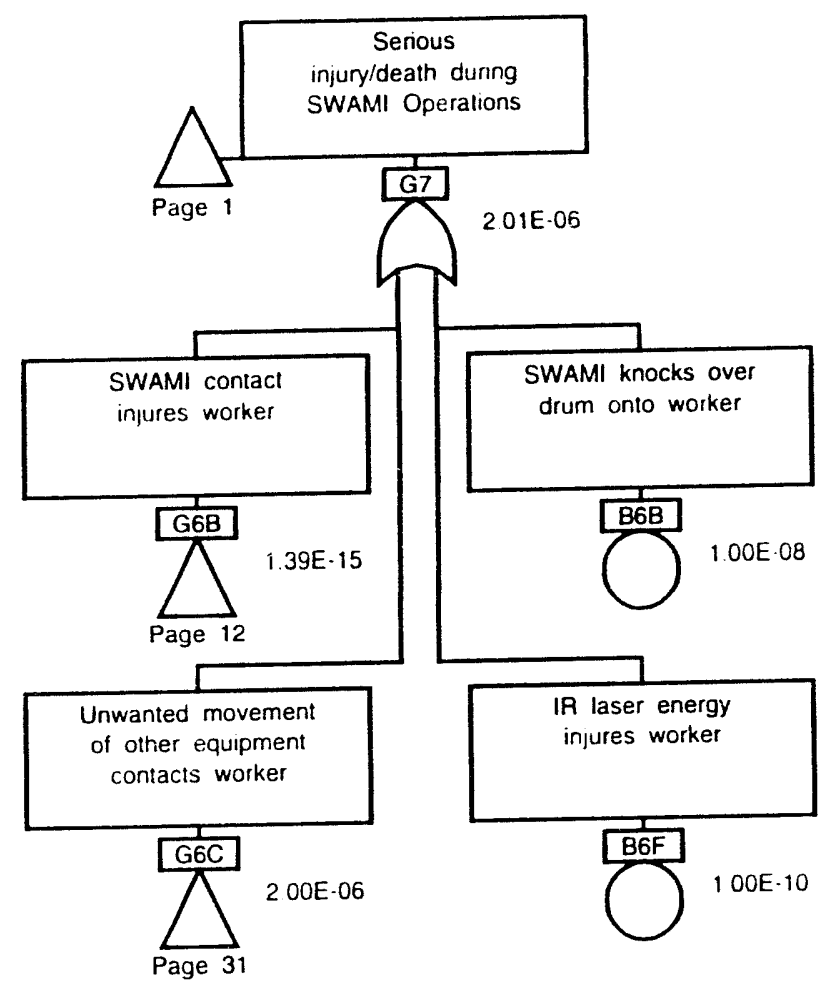




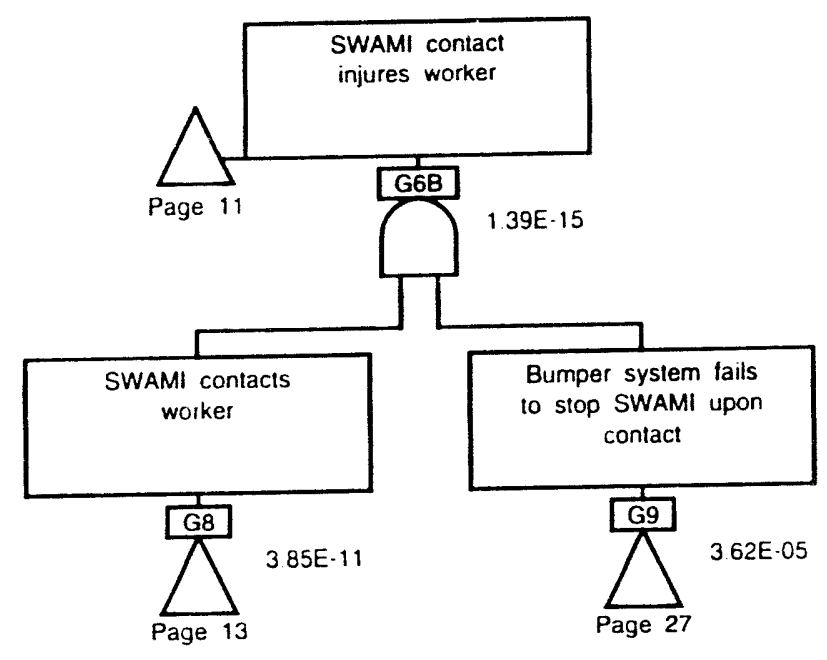




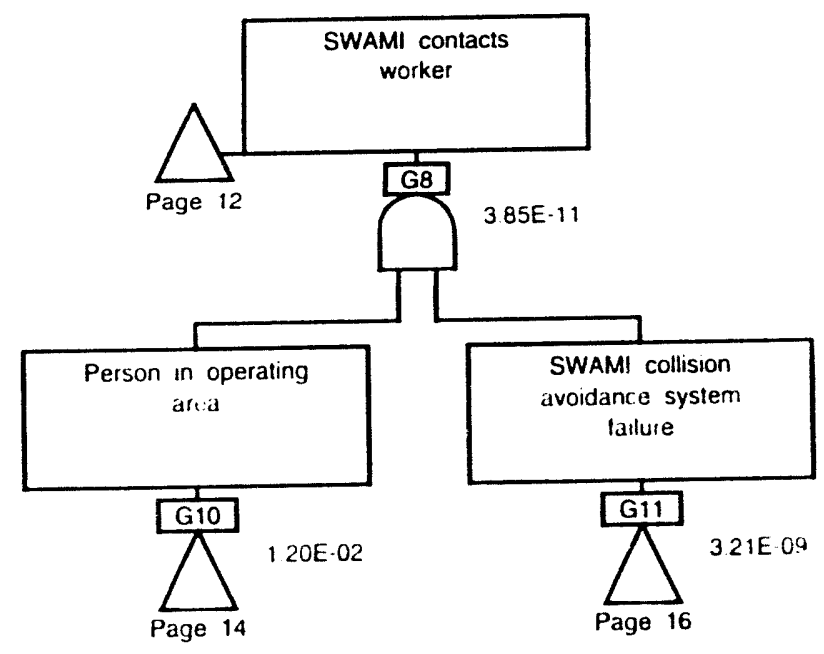




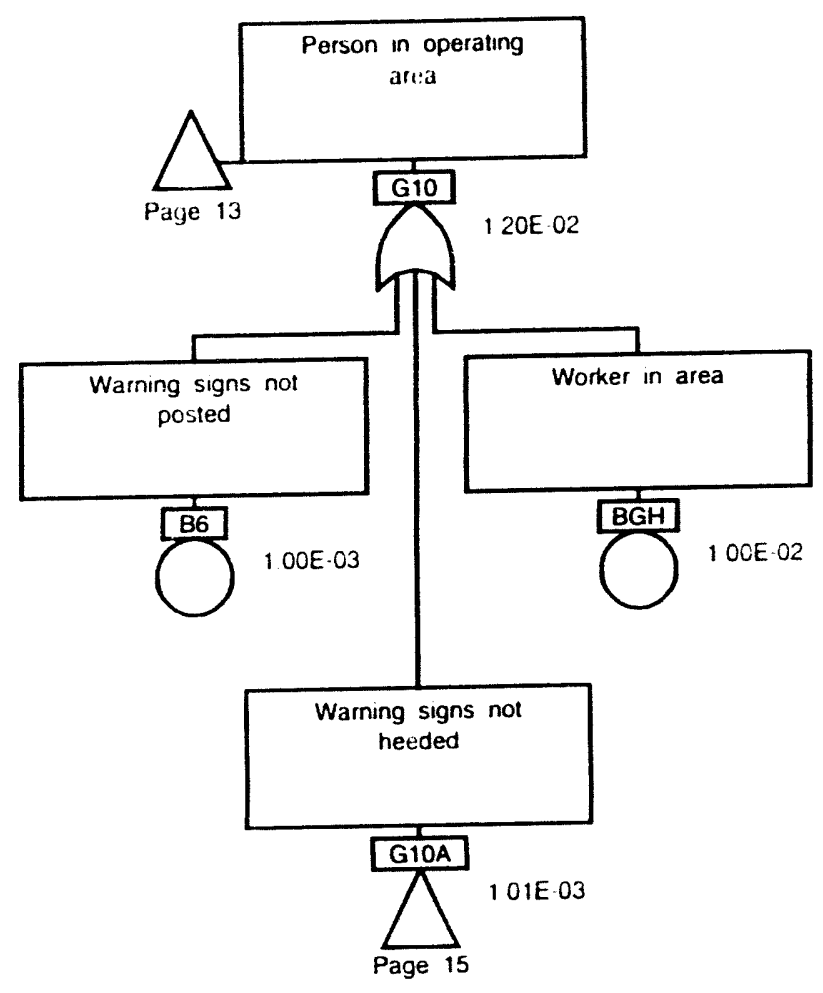




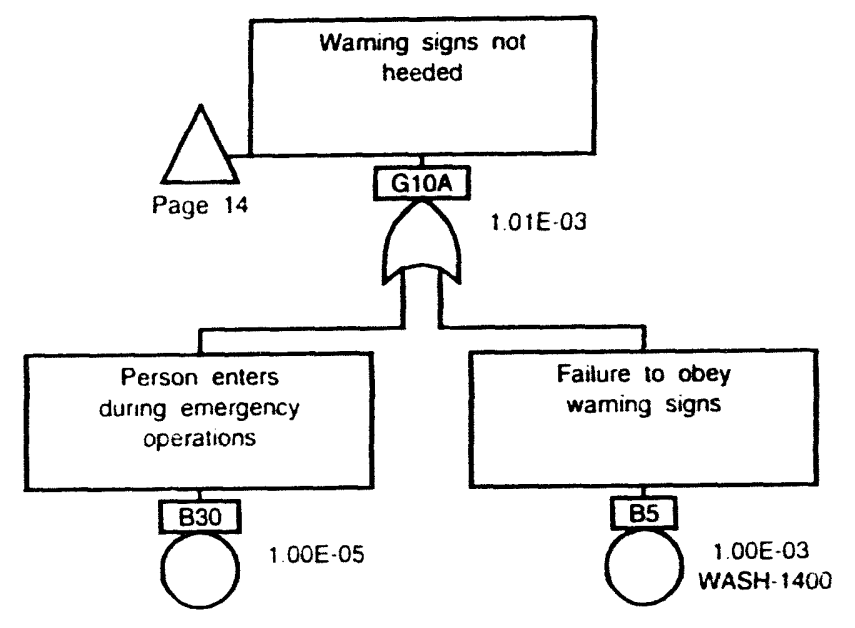




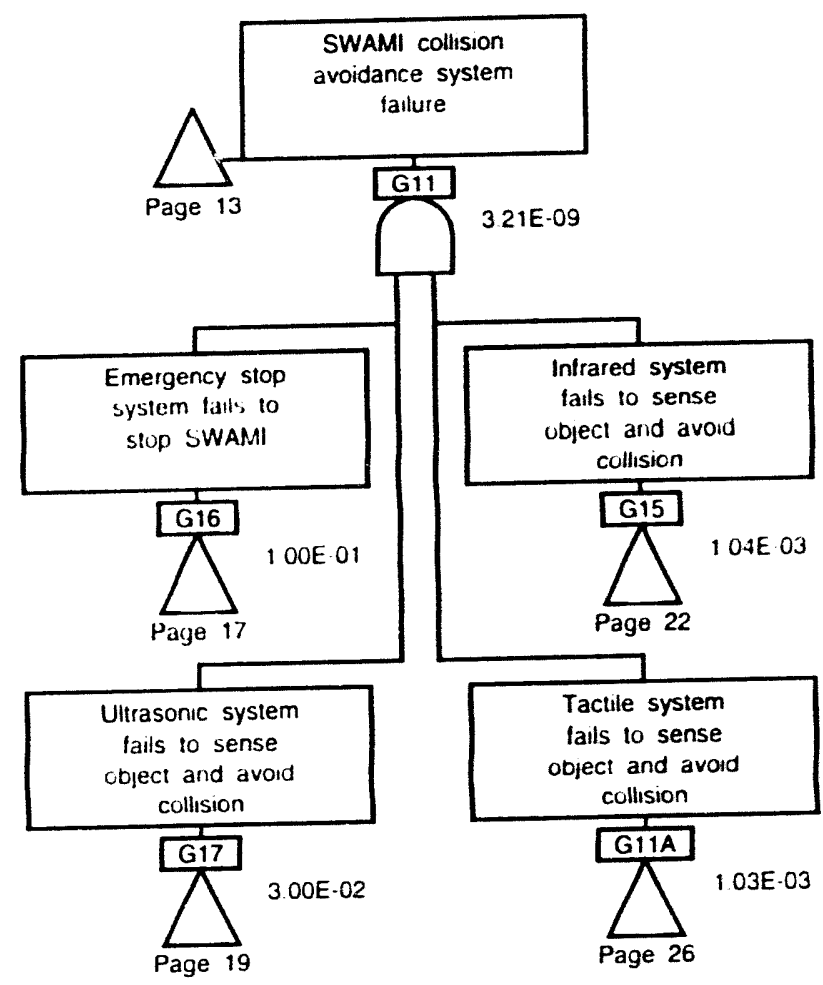




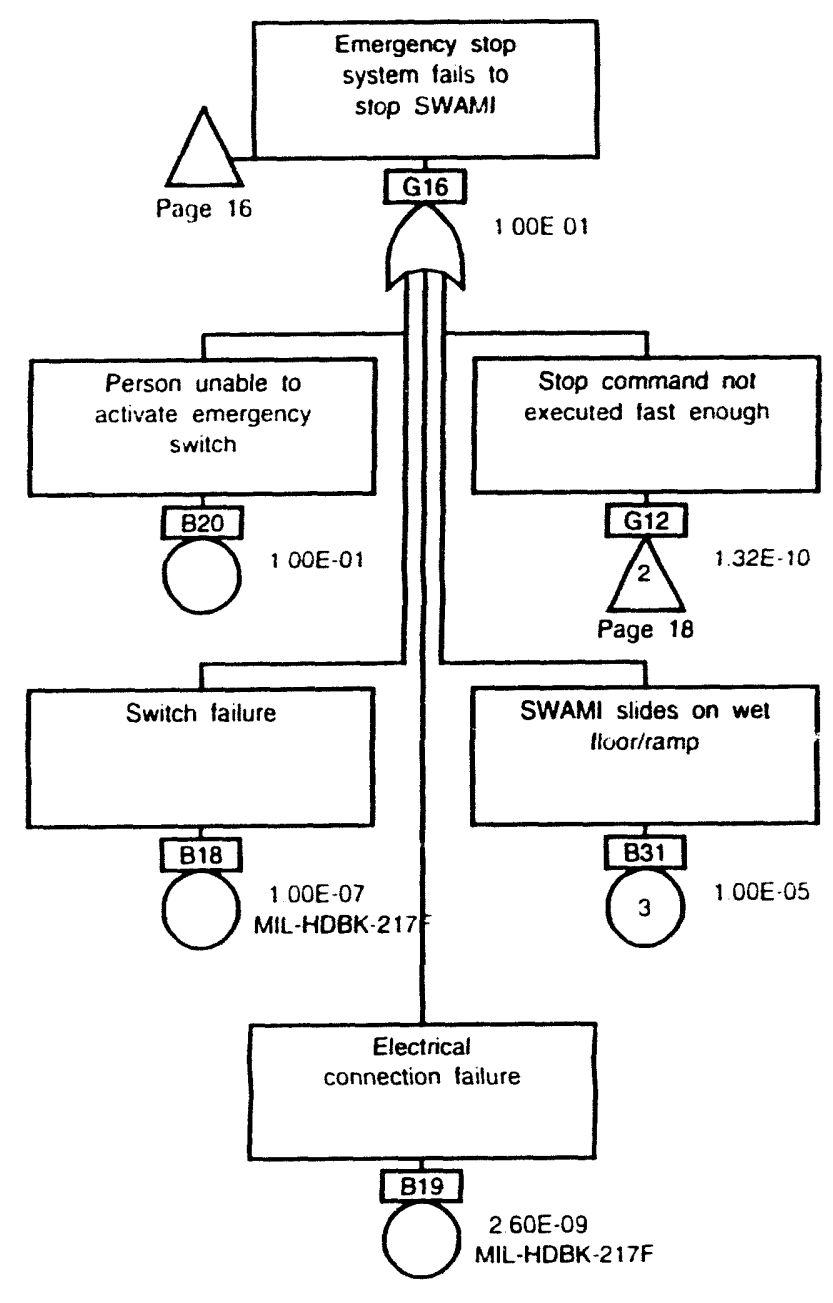




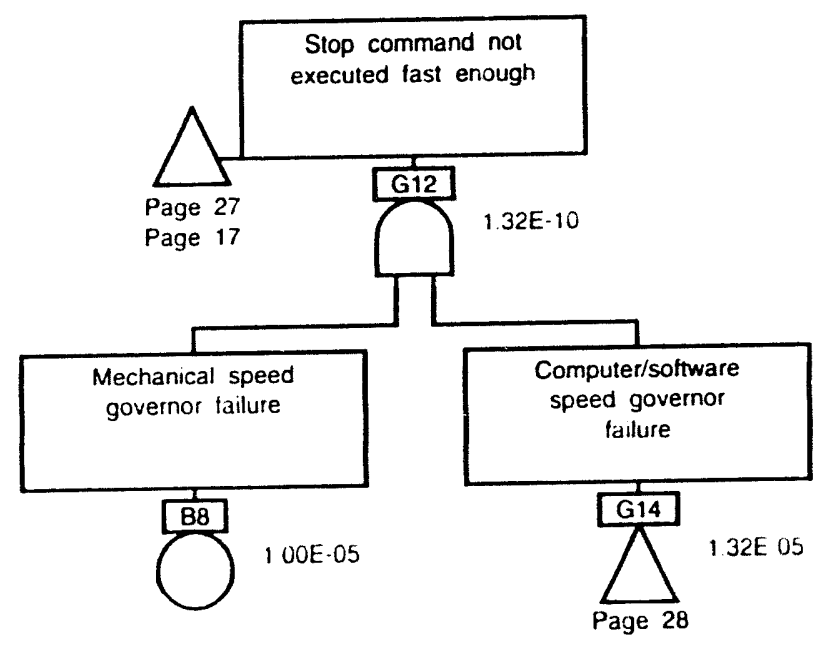




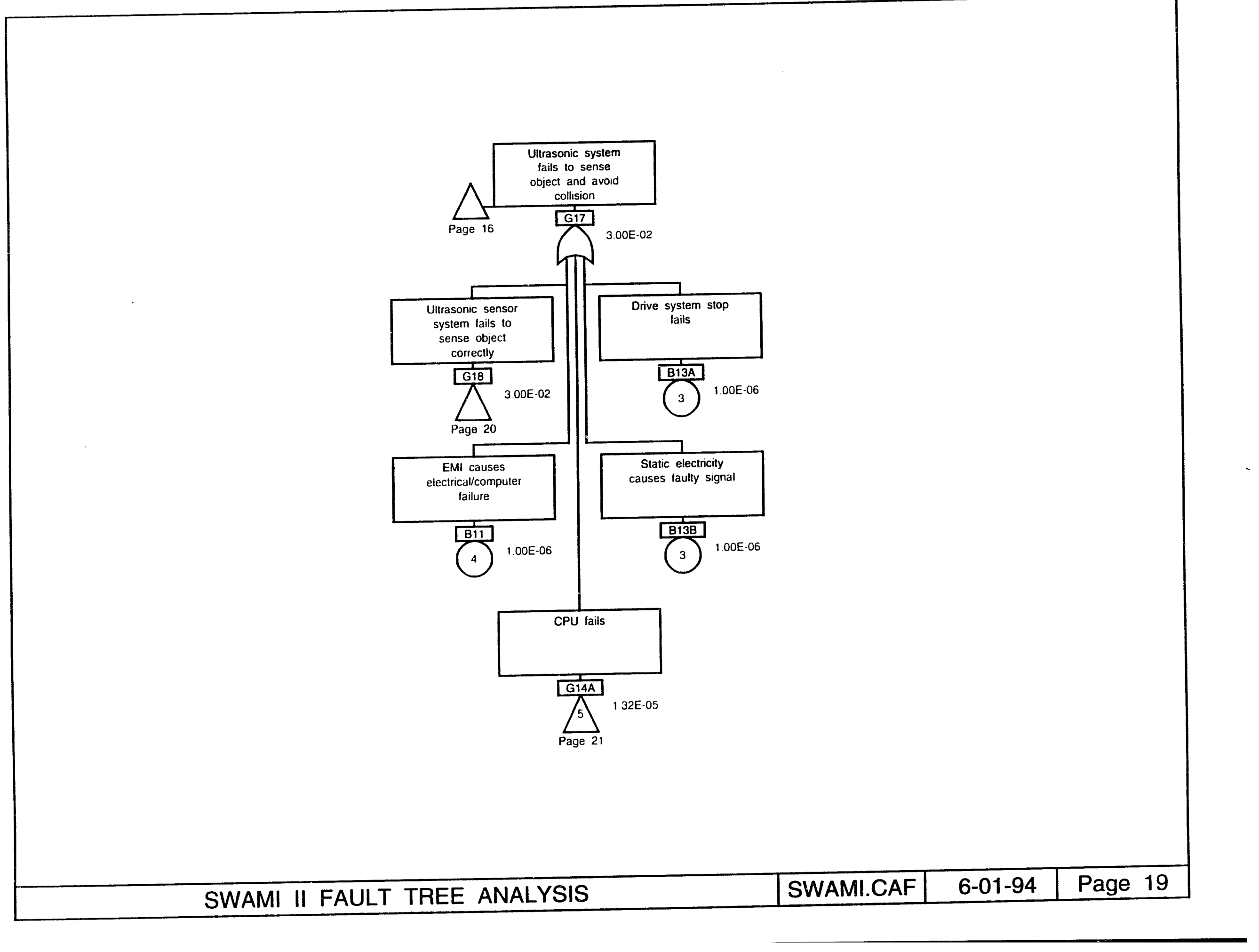




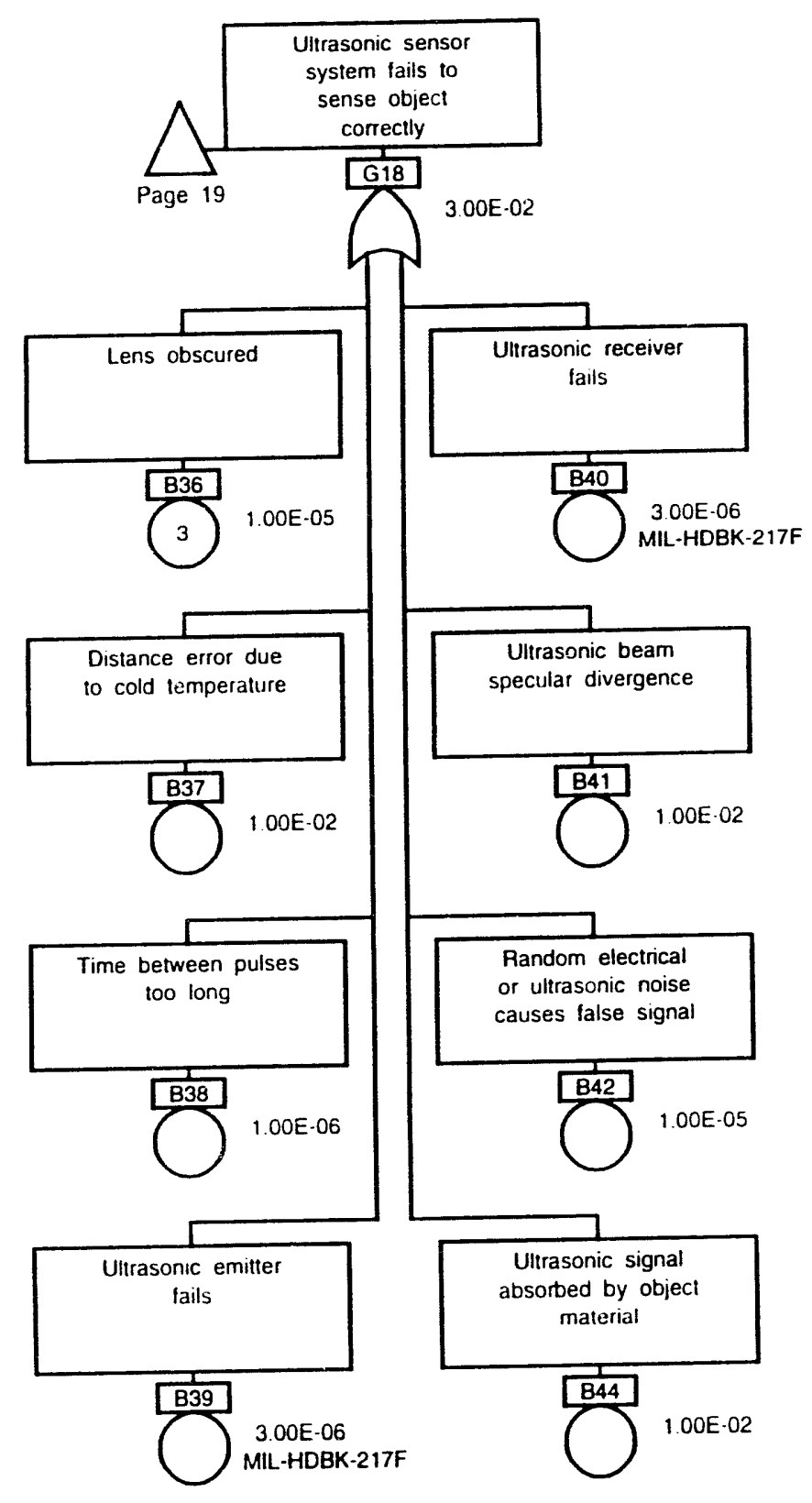




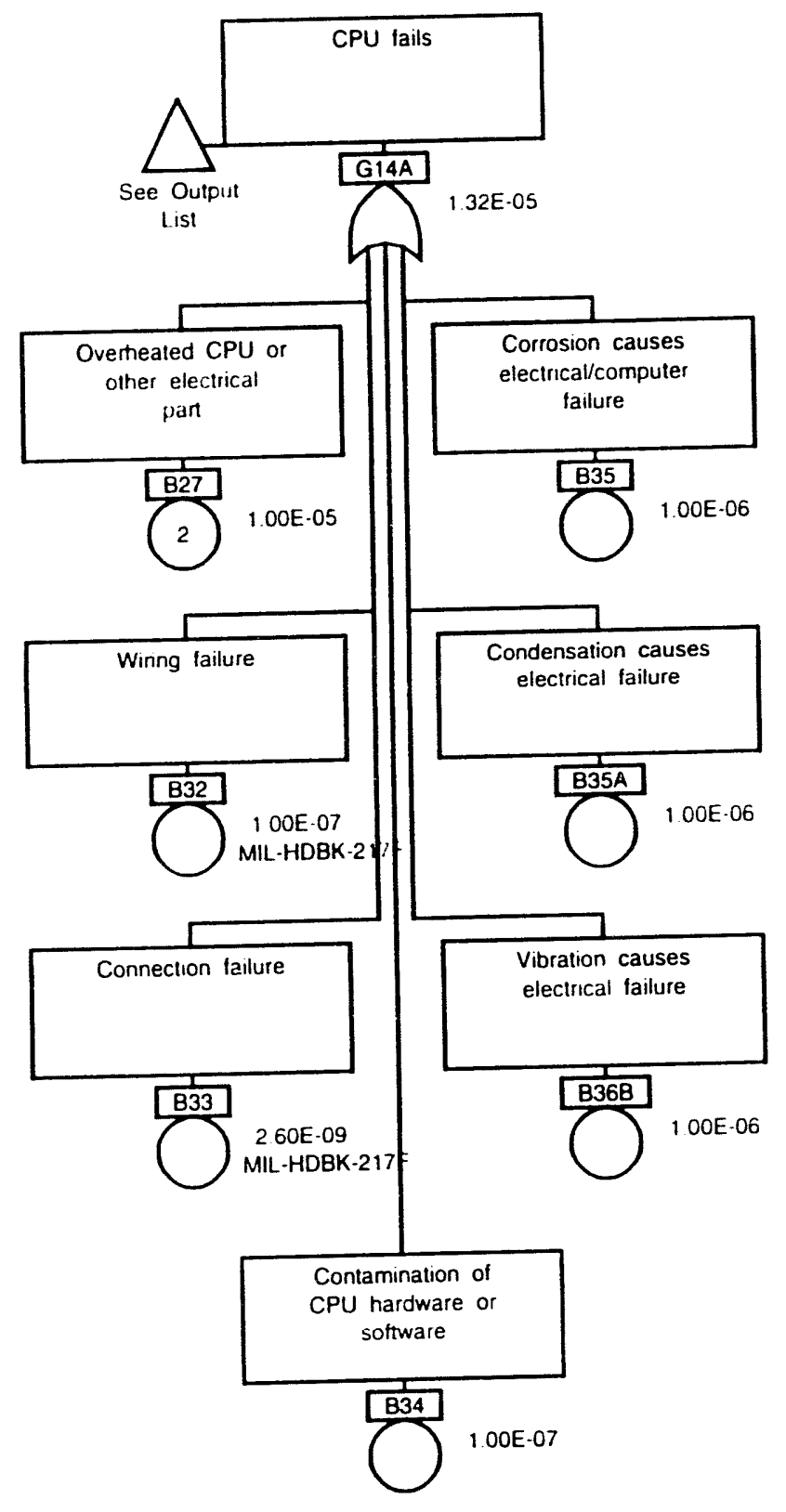




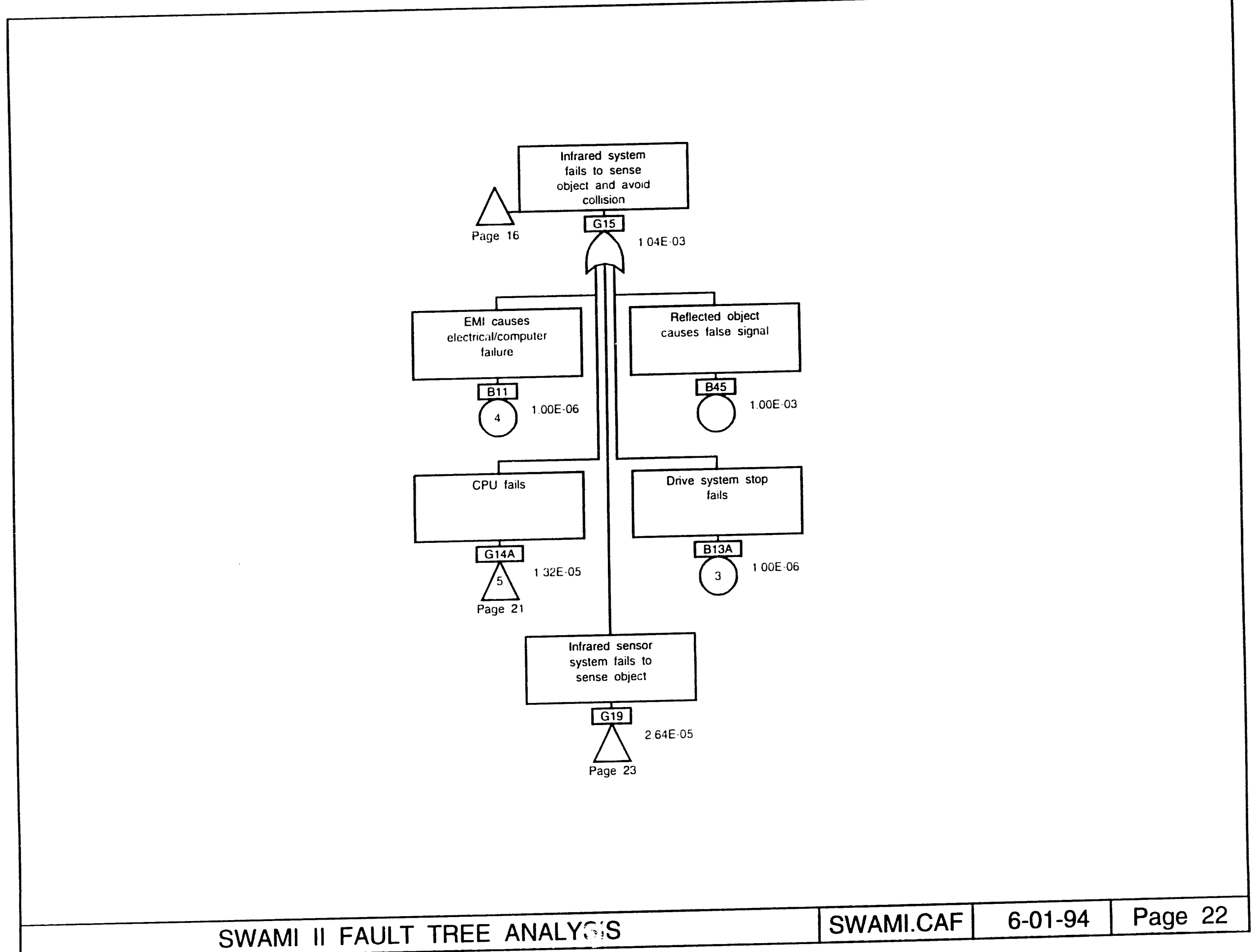




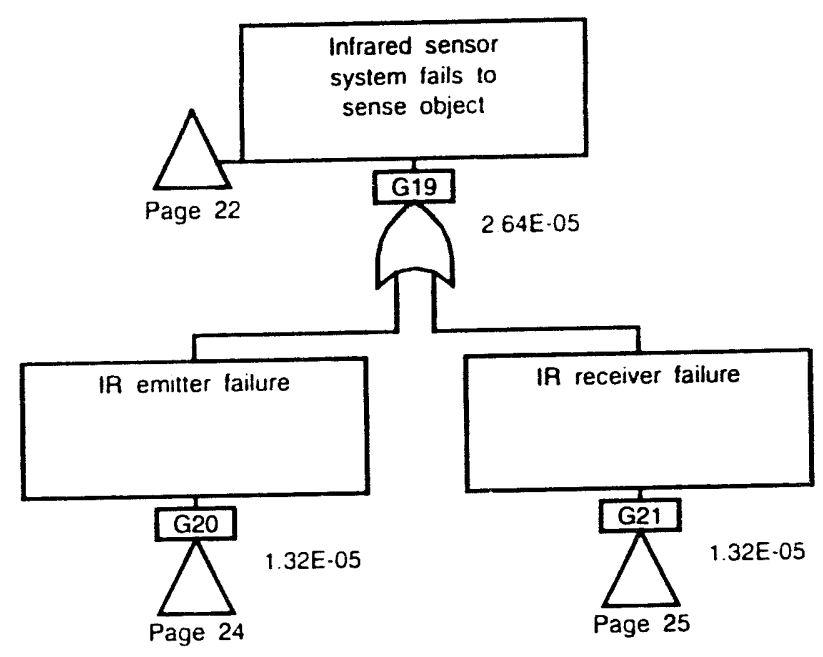




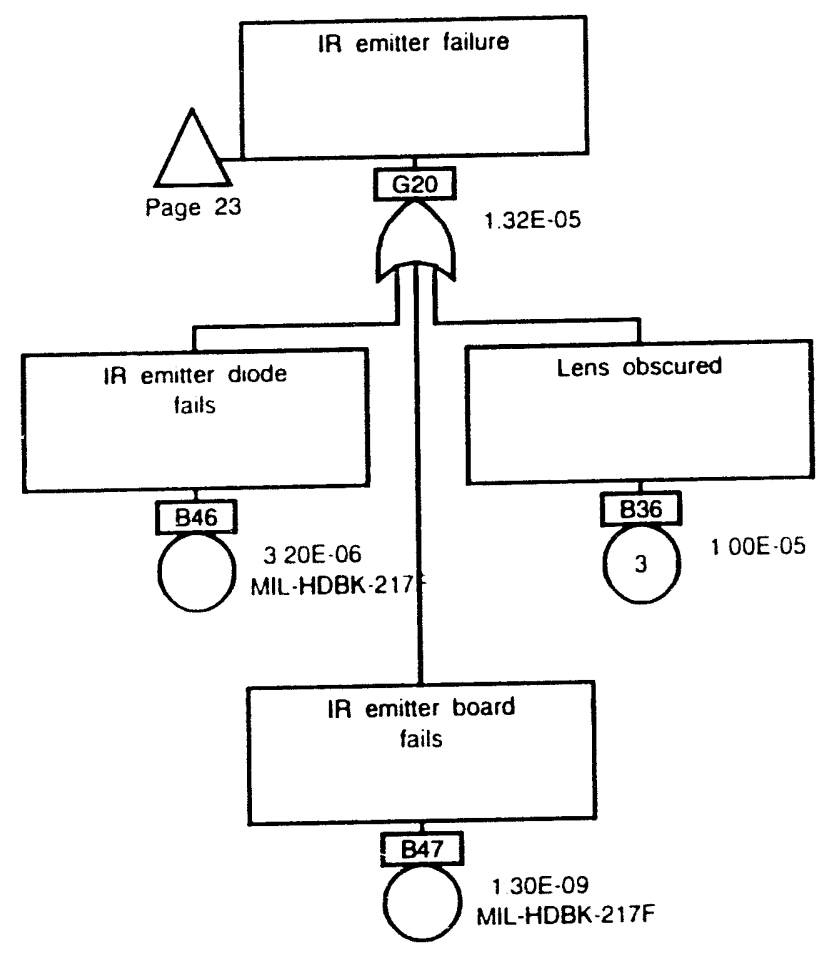




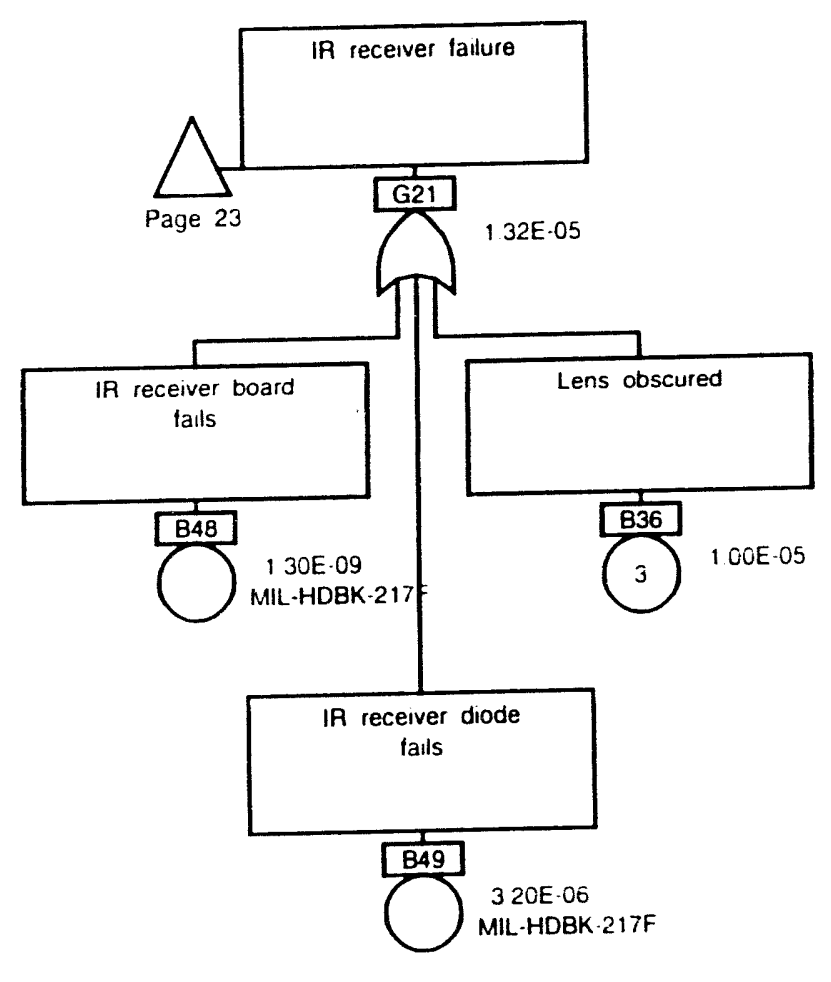




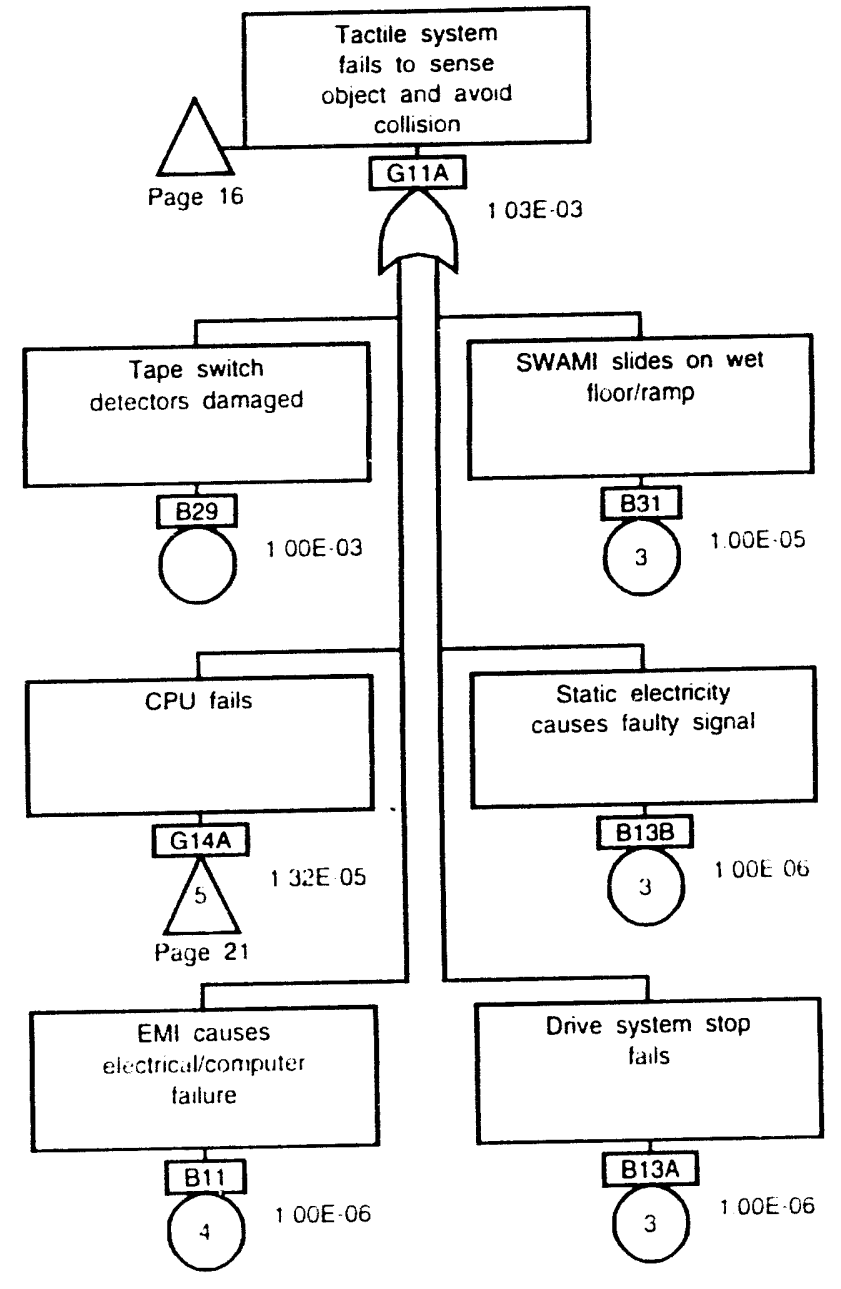




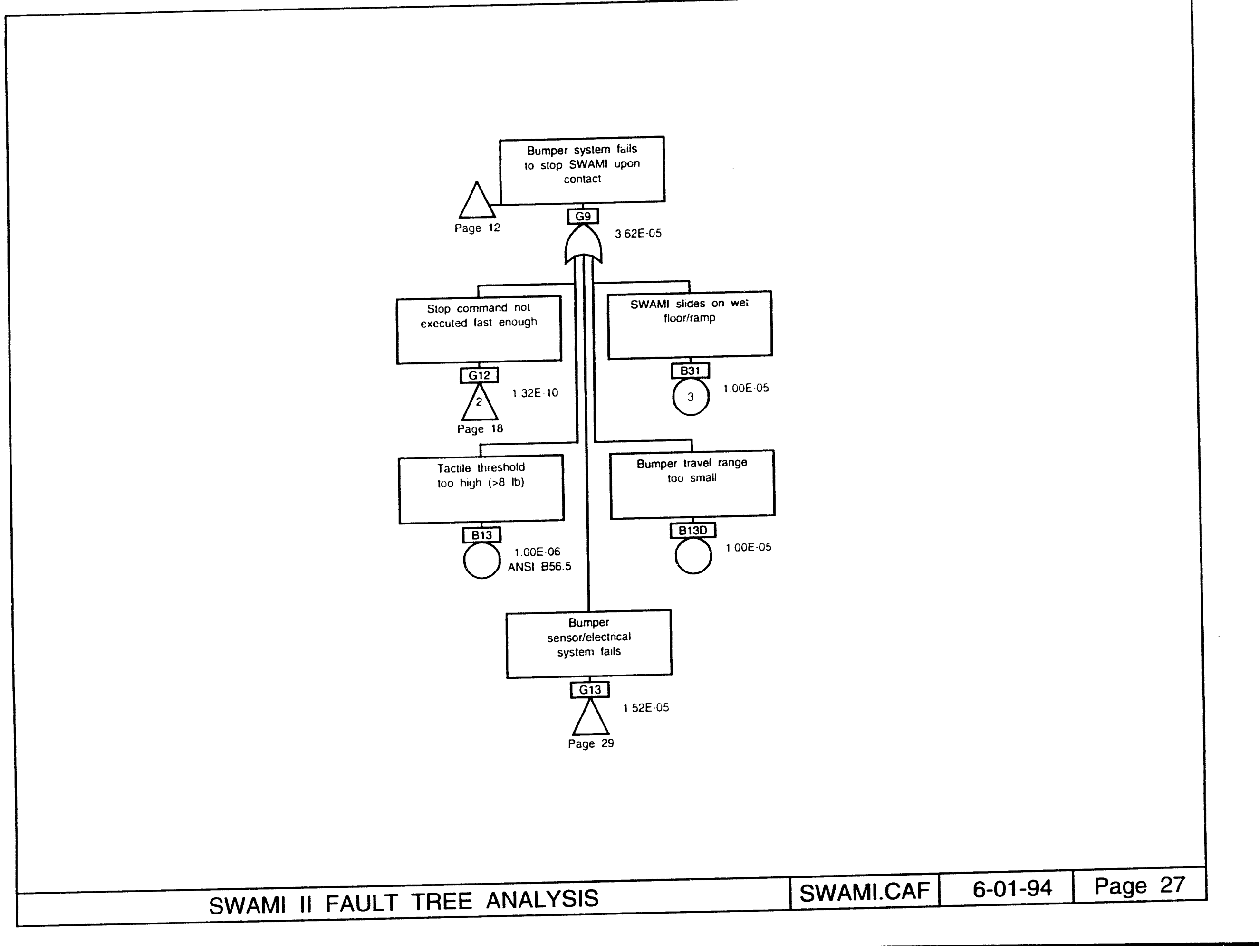




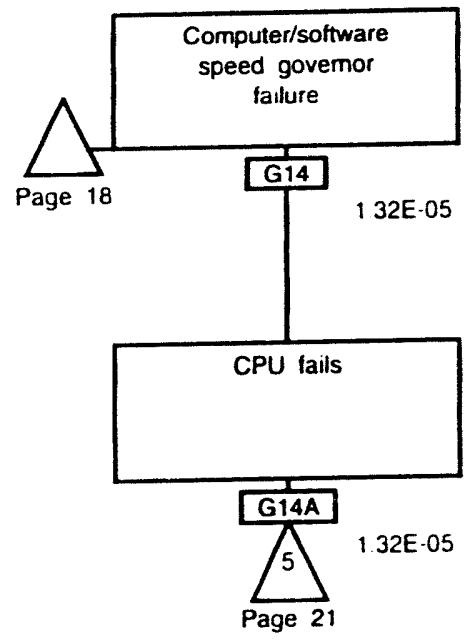




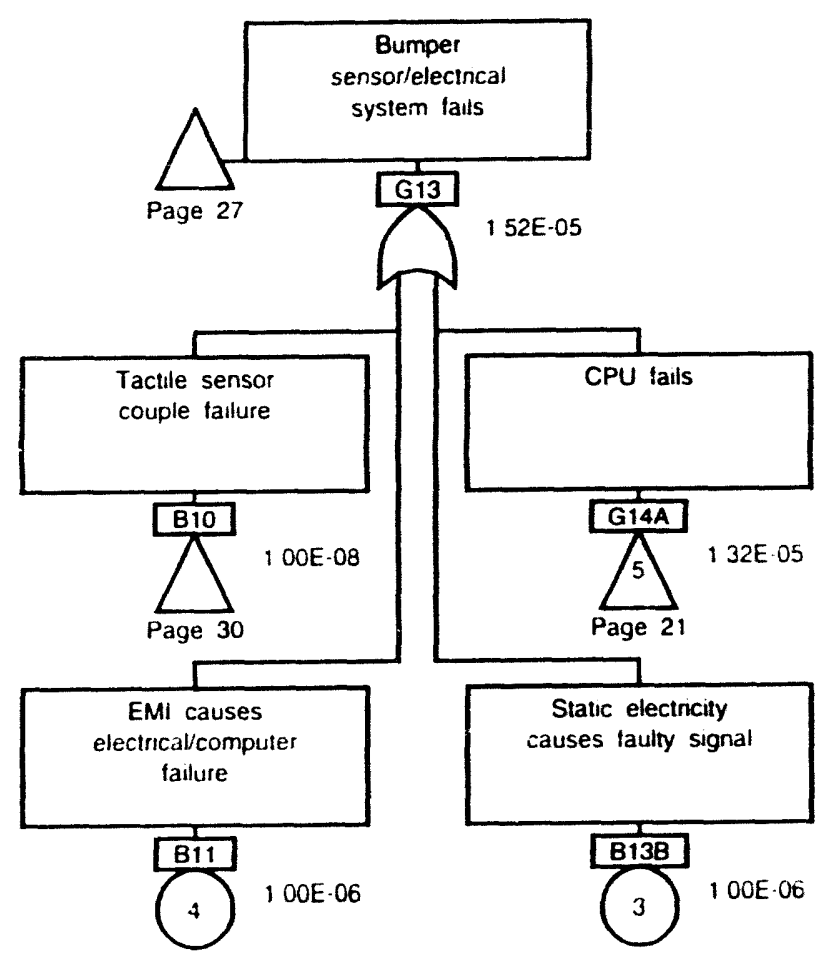




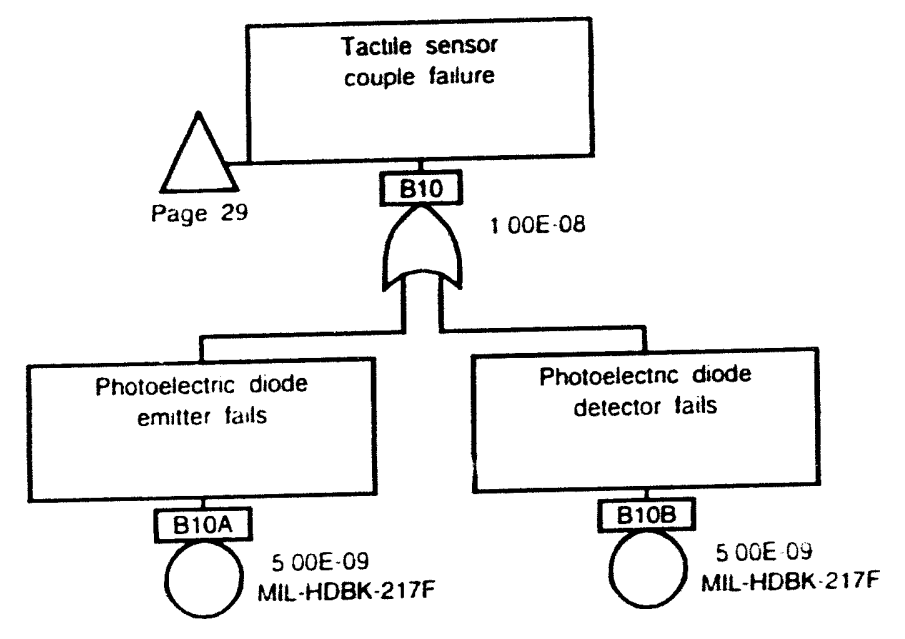




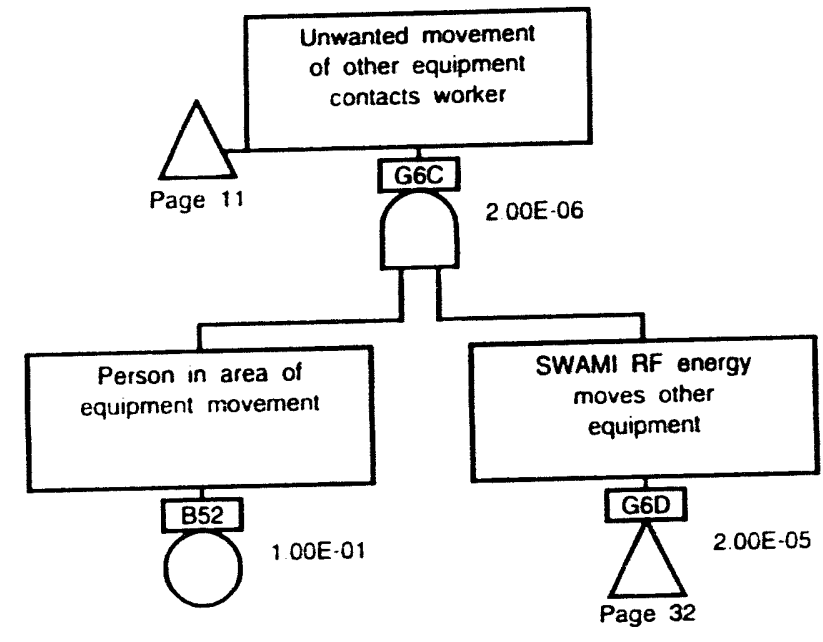




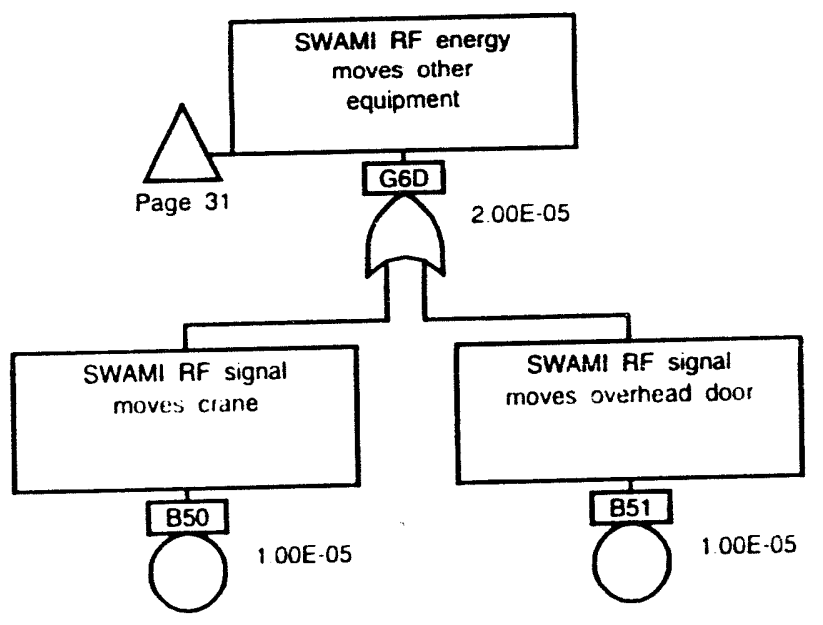



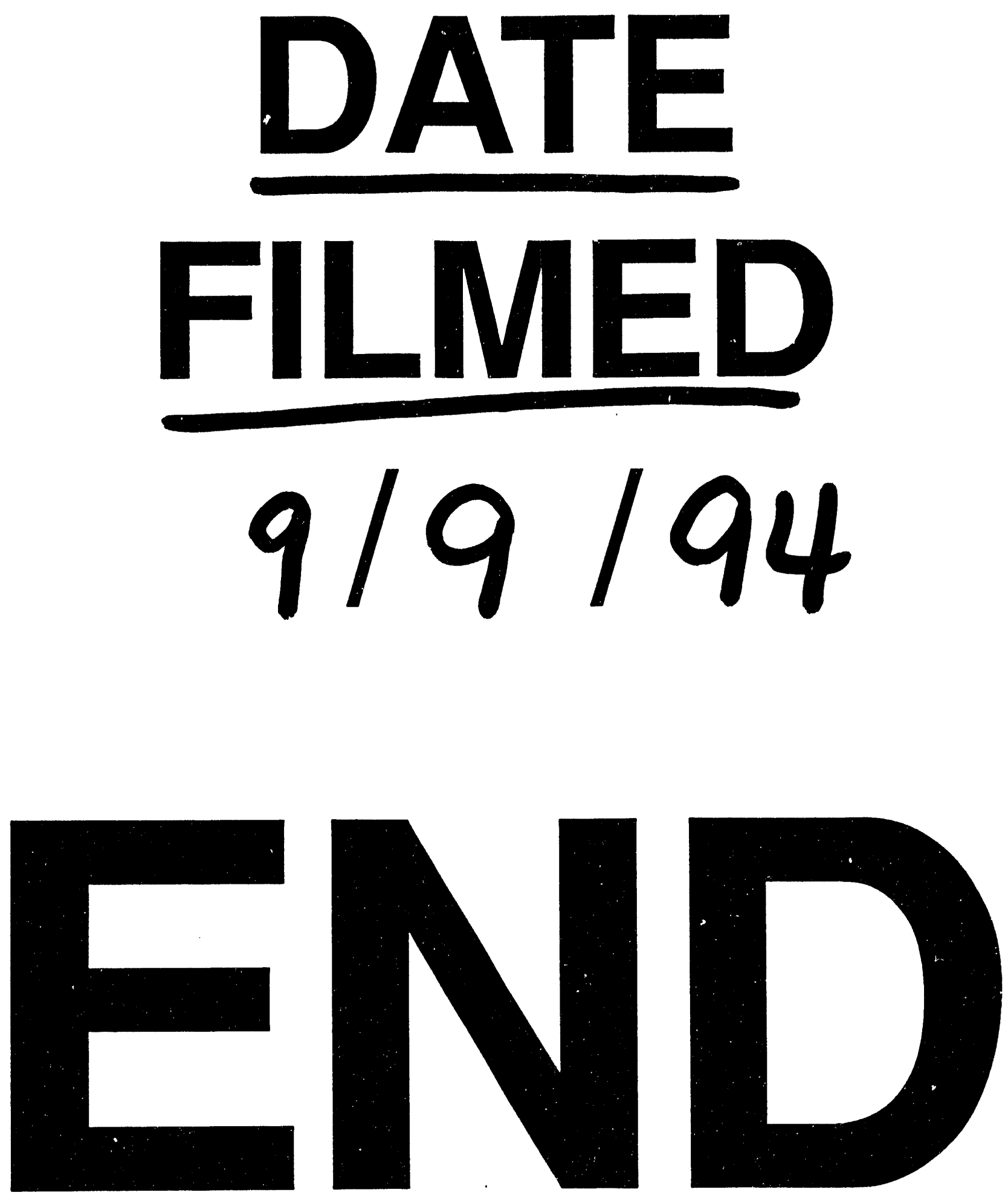
